\title{
Probing the formation of reactive oxygen species by a porous self-assembled benzophenone bis-urea host
}

Baillie A. DeHaven ${ }^{1}$, Hannah K. Liberatore ${ }^{1}$, Alexander Greer ${ }^{2,3}$, Susan D. Richardson ${ }^{1}$, and Linda S. Shimizu ${ }^{{ }^{*}}$

${ }^{1}$ Department of Chemistry and Biochemistry, University of South Carolina, Columbia, SC 29208

${ }^{2}$ Department of Chemistry, Brooklyn College, Brooklyn, NY

${ }^{3}$ Ph.D. Program in Chemistry, Graduate Center of City University of New York, NY

\section{Table of Contents}

General Methods $\quad \mathrm{S02}$

Synthesis of benzophenone bis-urea macrocycle (host 1) S03-06 Host 1 dimensions $\quad \mathrm{S} 07$

Decolorization of DMPO with methanol S08

1•DMPO spin trapping experiment of superoxide (methanol) S09

Easy Spin Simulation of DMPO-OOH adduct $\quad \mathrm{S} 10$

$\mathrm{BP} \cdot \mathrm{DMPO}$ spin trapping experiment of superoxide in (methanol) S11

1•DMPO spin trapping experiment of superoxide (Chloroform) $\quad \mathrm{S} 12$

$\mathrm{BP} \cdot \mathrm{DMPO}$ spin trapping experiment of superoxide (Chloroform) $\mathrm{S} 13$

1•TMP Singlet Oxygen Trapping Experiment (Chloroform) $\quad$ S14

BP•TMP Singlet Oxygen Trapping Experiment (Chloroform) $\quad$ S15

PN•TMP Singlet Oxygen Trapping Experiment (Chloroform) $\quad$ S16

Singlet Oxygen Quantum Yield Determination via EPR $\quad$ S17

Singlet Oxygen Quantum Yield Determination via UV-vis $\quad$ S18-20

Host:Guest Stoichiometry Determination by TGA S21

Photooxidation Procedures $\quad$ S22

GC-MS data of photooxidation in chloroform $\quad$ S23

GC-MS data of photooxidation in solid-state $\quad$ S24-25

GC-MS data of photooxidation in benzene $\quad$ S26

$\begin{array}{ll}\text { Singlet oxygen decay curve in air } & \text { S27 }\end{array}$

Direct detection of superoxide in acetonitrile $\quad$ S28

DMPO spin trapping study under argon (solid-state) $\quad$ S29

References $\quad$ S30 
GENERAL METHODS: All chemicals were purchased from Sigma Aldrich, VWR, or TCl Inc. and were used without further purification unless specified. ${ }^{1} \mathrm{H}-\mathrm{NMR}$ spectroscopy in solution was performed on a Bruker Avance III HD 300 NMR spectrometer. Samples were weighed out using a Mettler Toledo XPE206DR milligram balance. UV-irradiation of host 1 was carried out in a Rayonet RBR-200 UV reactor at $350 \mathrm{~nm}$ using RPR-3500A lamps in borosilicate vials or in quartz tubes. Thermogravimetric analysis (TGA) was carried out using TA instruments SDT-Q600 at a rate of $4 \% \mathrm{~min}$ from $25-180{ }^{\circ} \mathrm{C}$ (unless otherwise specified) with $15 \mathrm{~min}$ isotherms before and after temperature increase. Absorption spectra were recorded on a Molecular Devices Spectramax M2. GC-MS was carried out using Thermo Scientific (Waltham, MA) TRACE GC Ultra gas chromatograph coupled to a TSQ Quantum GC triple quadrupole mass spectrometer. Electron ionization mass spectral data was acquired in full scan mode of the first quadrupole from 33 to $650 \mathrm{~m} / \mathrm{z}$. Samples were splitless-injected $(1 \mu \mathrm{L})$ and an Rxi-5ms column ( $30 \mathrm{~m} \times 0.25 \mathrm{~mm} \times 0.25 \mu \mathrm{m})$ from Restek Corporation was used for chromatographic separations. The GC inlet was maintained at $250{ }^{\circ} \mathrm{C}$, with a helium flow rate of $1.2 \mathrm{~mL} / \mathrm{min}$. The transfer line and ion source were maintained at 280 and $200^{\circ} \mathrm{C}$, respectively. The GC oven was held at $35^{\circ} \mathrm{C}$ for $2 \mathrm{~min}$, then ramped to $100{ }^{\circ} \mathrm{C}$ at a rate of $5{ }^{\circ} \mathrm{C} / \mathrm{min}$, followed by a second ramp at $20^{\circ} \mathrm{C} / \mathrm{min}$ to a final temperature of $300^{\circ} \mathrm{C}$ and held for $15 \mathrm{~min}$.

EPR STUDIES: EPR experiments were performed using a Bruker EMX plus equipped with a Bruker X-band microwave bridgehead and Xenon software ( $\mathrm{v}$ 1.1b.66). All spectra were recorded using identical parameters at a power of $1.589 \mathrm{~mW}$ and modulation amplitude of $1.0 \mathrm{G}$. The double integration to obtain peak areas was performed three times and averaged in the Xenon software. Samples were sealed under pure ${ }^{3} \mathrm{O}_{2}(\mathrm{~g})$ and UV-irradiated in Norell Suprasil Quartz EPR tubes.

AIRBORNE ${ }^{1} \mathrm{O}_{2}$ LIFETIME MEASUREMENTS: An apparatus was constructed to deliver airborne ${ }^{1} \mathrm{O}_{2}$ to a trapping agent at its air/solid interface. The reactor consisted of a sensitizing glass plate made by depositing $\mathrm{Al}(\mathrm{III})$ phthalocyanine tetrasulfonate (AIPcS) $(\sim 50 \mu \mathrm{mol})$ onto the bottom side of a $0.50 \mathrm{~g}$ porous silica square (shape: $1.0 \mathrm{~mm} \times 2.25 \mathrm{~cm}^{2}$ ). A methanol solution containing $0.8 \mathrm{mM}$ of AlPcS was used to deposit the sensitizer on the bottom face of the plate, after which the methanol had evaporated after 0.5 to 1 day at $25^{\circ} \mathrm{C}$. The glass plate was placed sensitizer-face down on top of a custom-made plate containing a well (sized: $1 \mathrm{~mm} \times 1 \mathrm{~cm} \times 1 \mathrm{~cm}$ ). Approximately $10 \mathrm{mg}$ of solid trapping agent was placed in the well. The sensitizer plate was not in contact with the solid trapping agent and sat above it by $0.1 \mathrm{~mm}$. A digital ruler with a precision of $0.01 \mathrm{~mm}$ was used to measure the distance between the sensitizer plate and the solid trapping agent in the well. The sensitizer plate was placed $3.0 \mathrm{~cm}$ below the terminus of a multimode FT-400-EMT optical fiber with an SMA 905 connector (Thorlabs, Inc). The optical fiber was connected to a 630-nm light source from a Nd:YAG Qswitched laser pumping an optical parametric oscillator (OPO) producing 5-ns 
$\sim 0.2 \mathrm{~mJ} /$ pulses. The output of the $630-\mathrm{nm}$ light from the laser yielded incident photons in a Gaussian distribution upon the sensitizer plate. The airborne ${ }^{1} \mathrm{O}_{2}$ luminescence was detected by a photomultiplier tube (H10330A-45, Hamamatsu Corp.) through a 1270-nm bandpass filter $(\mathrm{FWHM}=15 \mathrm{~nm})$. The airborne ${ }^{1} \mathrm{O}_{2}$ luminescence signals were registered on a $600 \mathrm{MHz}$ oscilloscope and the kinetic data for the airborne ${ }^{1} \mathrm{O}_{2}$ lifetime ( $\left.\tau_{\Delta \text { airborne }}\right)$ was determined by a least-squares curve-fitting with a nonlinear least-squares procedure in Origin Software. ${ }^{1}$

\section{General Synthetic Procedure}<smiles>Cc1ccc(C(=O)c2ccc(C)cc2)cc1</smiles>

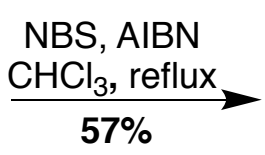<smiles>O=C(c1ccc(CBr)cc1)c1ccc(CBr)cc1</smiles><smiles>CC(C)(C)N1CNC(=O)NC1</smiles>

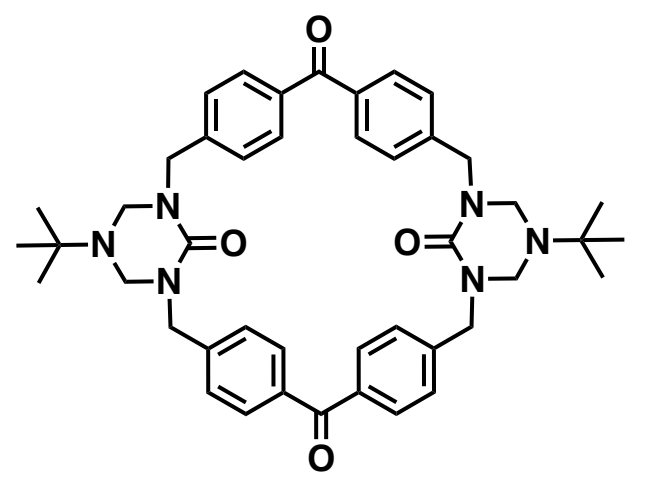<smiles>COCCNCCOCCOC(=O)NCc1ccc(C(=O)c2ccc(CNC(=O)NCc3ccc(C(=O)c4ccc(CNC(=O)NCCO)cc4)cc3)cc2)cc1</smiles>

Scheme S1. Host 1 was synthesized as previously reported. ${ }^{2-4}$ Commercial 4,4'dimethylbenzophenone was brominated with $\mathrm{N}$-bromosuccinimide (NBS) using 2,2'-azobis(isobutyronitrile) (AIBN) as an initiator in $\mathrm{CHCl}_{3}$ to yield 4,4'bis(bromomethyl)benzophenone. The brominated benzophenone was then cyclized with triazinanone and $\mathrm{NaH}$ in refluxing $\mathrm{THF}$ to form the protected macrocycle, which was subsequently deprotected in an acidic diethanol amine aqueous/methanol mixture to afford the desired macrocycle 1. 


\section{Synthesis of 4,4'-bis(bromomethyl)benzophenone}<smiles>Cc1ccc(C(=O)c2ccc(C)cc2)cc1</smiles>

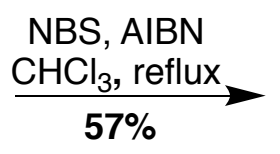<smiles>O=C(c1ccc(CBr)cc1)c1ccc(CBr)cc1</smiles>

4,4'-dimethylbenzophenone (2.00 g, $9.51 \mathrm{mmol}, 1 \mathrm{eq})$ was dissolved in chloroform (30 mL). Next, N-bromosuccinimide (NBS, $4.23 \mathrm{~g}, 23.8 \mathrm{mmol}, 2.5 \mathrm{eq}$ ) and azobisisobutyronitrile (AIBN, $0.01 \mathrm{~g}, 0.06 \mathrm{mmol}, 0.01 \mathrm{eq}$ ) were added, and the reaction mixture was heated at reflux under $\mathrm{N}_{2}$ for $18 \mathrm{~h}$. Excess AIBN $(\sim 2$ $\mathrm{mg}$ ) and NBS ( $\sim 30 \mathrm{mg}$ ) were added to the reaction mixture, which was stirred for a further two hours to push the reaction to completion. The reaction was cooled to room temperature and succinimide was extracted with DI water $(3 \times 50 \mathrm{~mL})$ and the chloroform layer was dried under $\mathrm{MgSO}_{4}$. Silica gel was added, and the solvent was removed under vacuum and loaded onto a silica gel column packed with hexanes. The product was isolated via column chromatography mixture as the last spot to yield a white solid, the column was performed using a gradient of hexanes and ethyl acetate, beginning with pure hexanes and slowly tapering to a 9:1 hexanes: ethyl acetate mixture (57\%). ${ }^{1} \mathrm{H}-\mathrm{NMR}:\left(300 \mathrm{MHz} ; \mathrm{CDCl}_{3}\right) \delta=7.78$ $(4 \mathrm{H}, \mathrm{d}, \mathrm{J}=8.1), 7.51(4 \mathrm{H}, \mathrm{d}, \mathrm{J}=8.4), 4.54(4 \mathrm{H}, \mathrm{s})$.

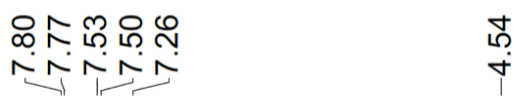<smiles>Cc1ccc(C(=O)c2ccc(CBr)cc2)cc1</smiles>

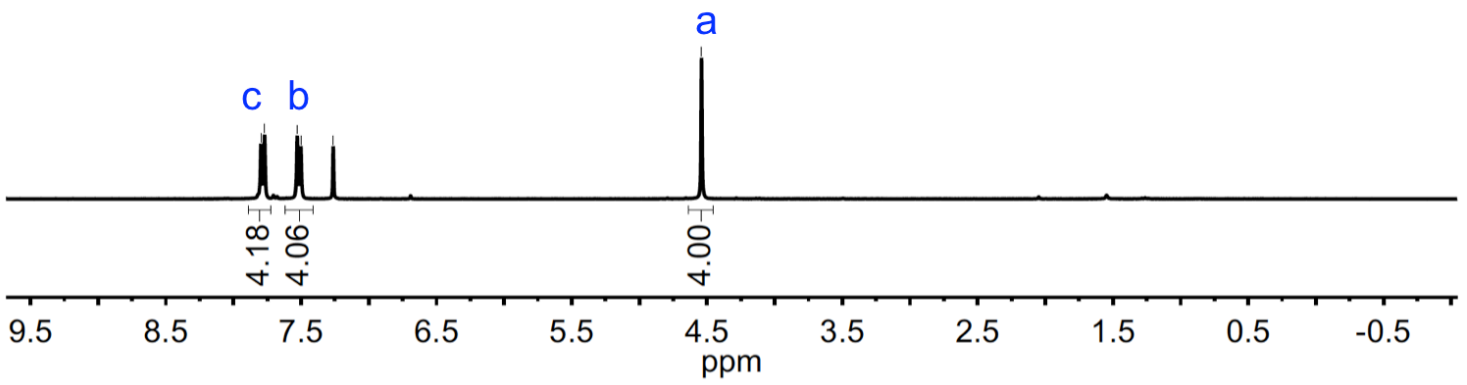

Figure S1. ${ }^{1} \mathrm{H}$ NMR of $4,4^{\prime}$-bis(bromomethyl)benzophenone in $\mathrm{CDCl}_{3}$. 


\section{Synthesis of protected bis-urea benzophenone macrocycle 1}

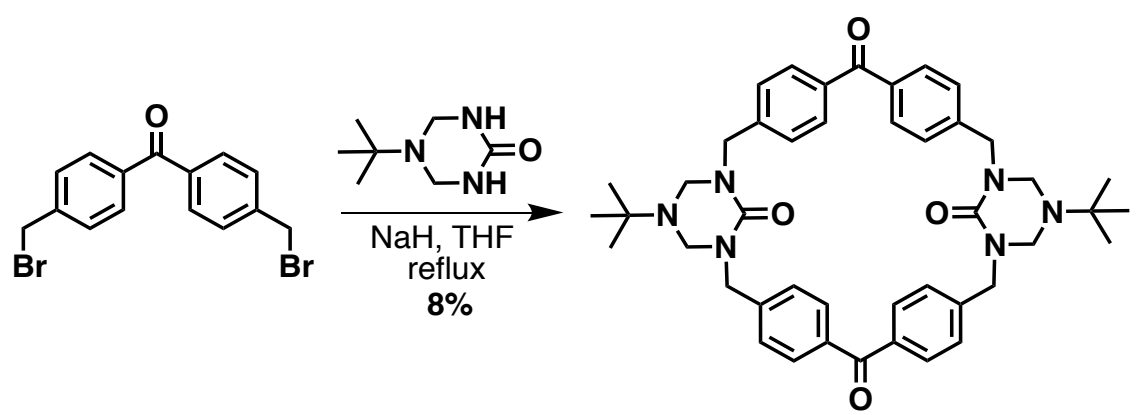

To a dry round bottom flask, still-dried THF $(400 \mathrm{~mL})$ was added. Next, triazinanone $(0.86 \mathrm{~g}, 5.43 \mathrm{mmol})$ and $\mathrm{NaH}(60 \%$ suspension in mineral oil, 0.88 $\mathrm{g}, 21.72 \mathrm{mmol}$ ) were added. The mixture was heated to reflux under $\mathrm{N}_{2}$ atmosphere for two hours. The suspension was cooled to room temperature and a solution of 4,4'-bis(bromomethyl)benzophenone $(2.01 \mathrm{~g}, 5.43 \mathrm{mmol}$ in dry THF $(100 \mathrm{~mL})$ was added to the stirring mixture all at once. The mixture was then heated to reflux for $48 \mathrm{~h}$. Next, the reaction mixture was cooled to room temperature, neutralized with $1 \mathrm{~N} \mathrm{HCl}(\sim 10 \mathrm{~mL})$, and diluted with water $(100 \mathrm{~mL})$. THF was then removed under vacuum until an aqueous suspension remained. Crude product was extracted with methylene chloride $(3 \times 100 \mathrm{~mL})$, washed with brine $(150 \mathrm{~mL})$, and dried with anhydrous $\mathrm{Mg}_{2} \mathrm{SO}_{4}$. Product was purified via flash silica gel column chromatography (9:1 ethyl acetate: methanol). Column fractions were left to evaporate for 3-7 days and a white precipitate was collected and dried under vacuum to yield a white solid. $(0.16 \mathrm{~g}, 8 \%)$. ${ }^{1} \mathrm{H}-\mathrm{NMR}(300 \mathrm{MHz}$, $\left.\mathrm{CD}_{2} \mathrm{Cl}_{2}\right) \delta 7.81(\mathrm{~d}, \mathrm{~J}=8.3,8 \mathrm{H}), 7.46(\mathrm{~d}, \mathrm{~J}=8.3,8 \mathrm{H}), 4.65(\mathrm{~s}$, broad, $8 \mathrm{H}), 4.35(\mathrm{~s}$, $8 \mathrm{H}), 1.07(\mathrm{~s}, 18 \mathrm{H})$.

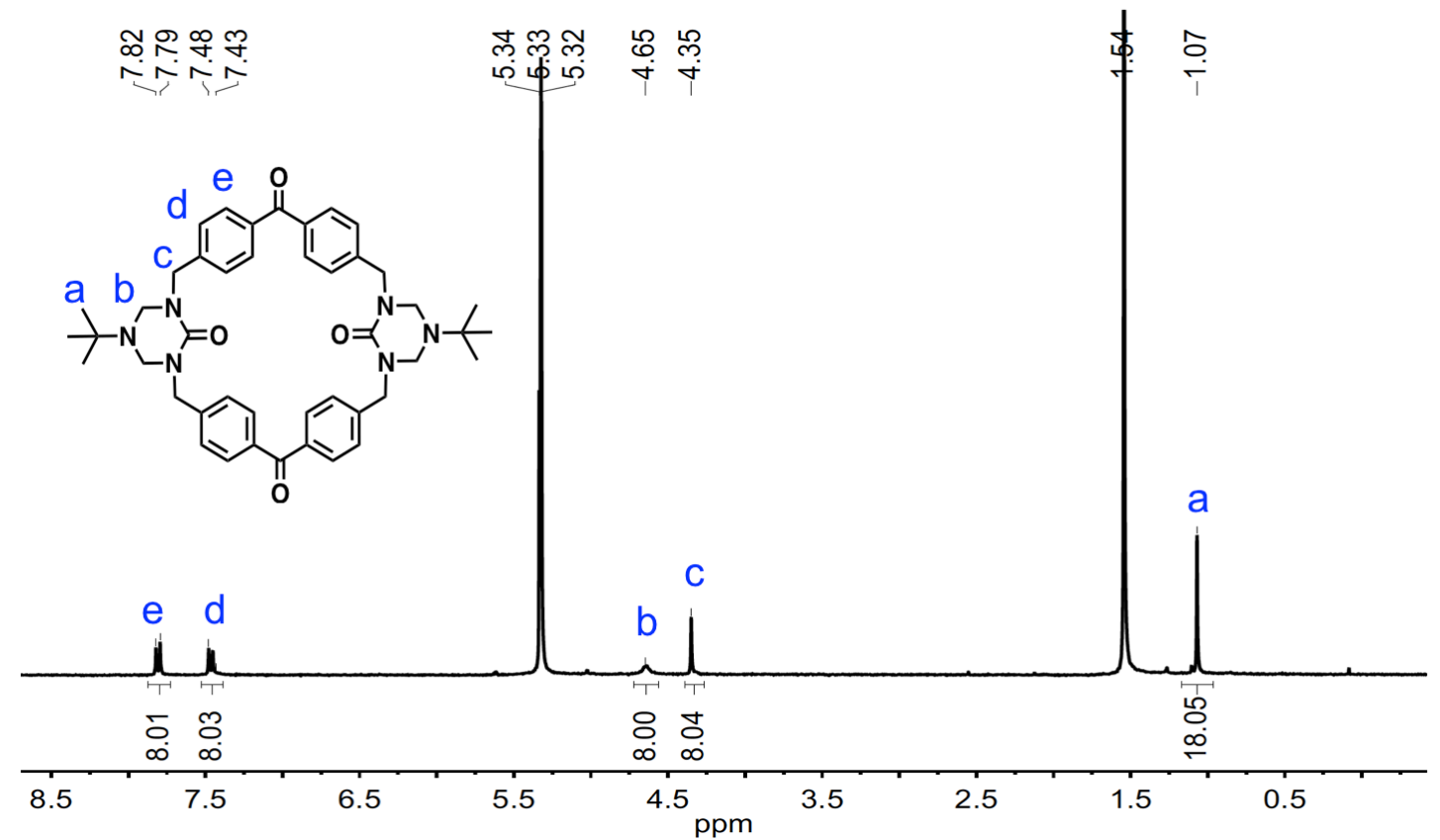

Figure S2. ${ }^{1} \mathrm{H}$ NMR of protected benzophenone bis-urea macrocycle 1 in $\mathrm{CD}_{2} \mathrm{Cl}_{2}$. 


\section{Preparation of Deprotection Solution:}

A mixture of diethanol amine $(20 \mathrm{~mL})$ and deionized water $(50 \mathrm{~mL})$ was adjusted to $\mathrm{pH} 2$ via drop-wise addition of $12.1 \mathrm{~N} \mathrm{HCl}$. The $\mathrm{pH}$ was monitored via litmus paper.

\section{Deprotection of protected benzophenone bis-urea macrocycle (1)}

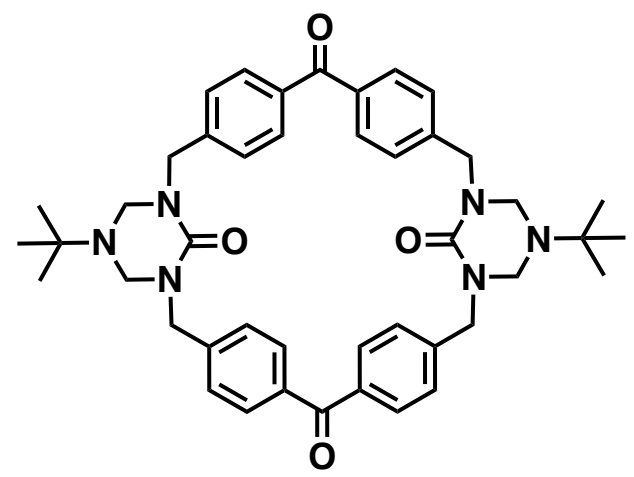<smiles>COC(=O)OCCOCCOC(=O)NCc1ccc(C(=O)c2ccc(CNC(=O)NCc3ccc(C(=O)c4ccc(CNCCO)cc4)cc3)cc2)cc1</smiles>

Triazinanone protected bis-urea benzophenone macrocycle $(0.200 \mathrm{~g}, 0.28 \mathrm{mmol})$ was added to $1: 1 \mathrm{v} / \mathrm{v}$ mixture of the deprotection solution $(70 \mathrm{~mL})$ and methanol $(70 \mathrm{~mL}$ ) was refluxed as a suspension for $48 \mathrm{~h}$. The precipitate (varying in color from yellow to white) was collected via vacuum filtration and was washed with $1 \mathrm{~N}$ $\mathrm{HCl}(20 \mathrm{~mL})$, distilled water $(3 \times 100 \mathrm{~mL})$, and dried under vacuum $(0.135 \mathrm{~g}$, 92\%). ${ }^{1} \mathrm{H}-\mathrm{NMR}(300 \mathrm{MHz}$, DMSO- 66$) \delta 7.75$ (d, $\left.J=8.3,8 \mathrm{H}\right), 7.43$ (d, $\left.J=8.3,8 \mathrm{H}\right)$, $6.82(\mathrm{t}, \mathrm{J}=6.2,4 \mathrm{H}), 4.38(\mathrm{~d}, \mathrm{~J}=5.9,8 \mathrm{H})$

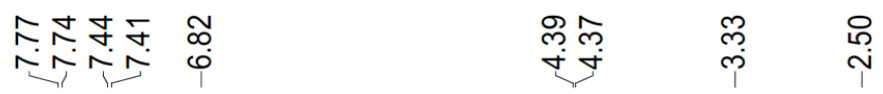

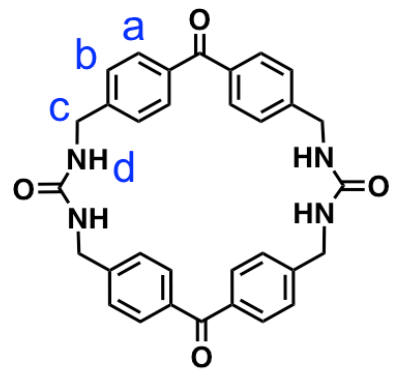

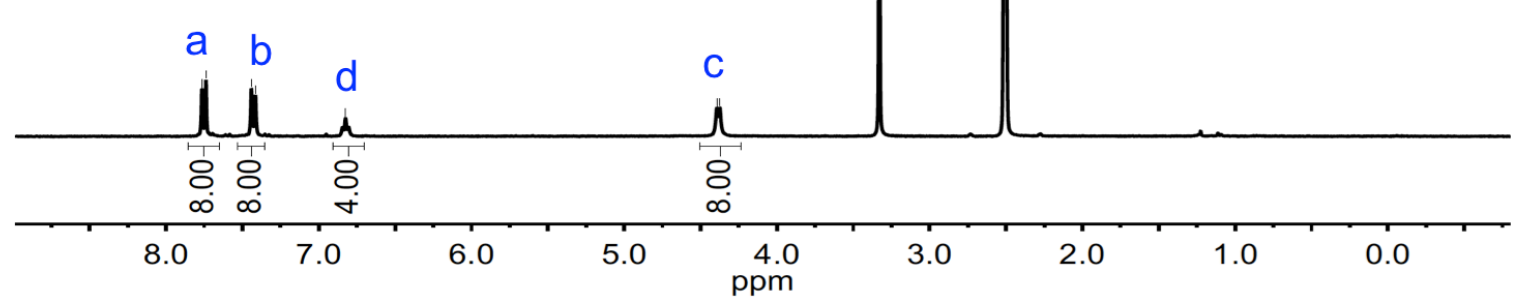

Figure S3. ${ }^{1} \mathrm{H}$ NMR of benzophenone bis-urea macrocycle 1 in $\delta 6$-DMSO. 


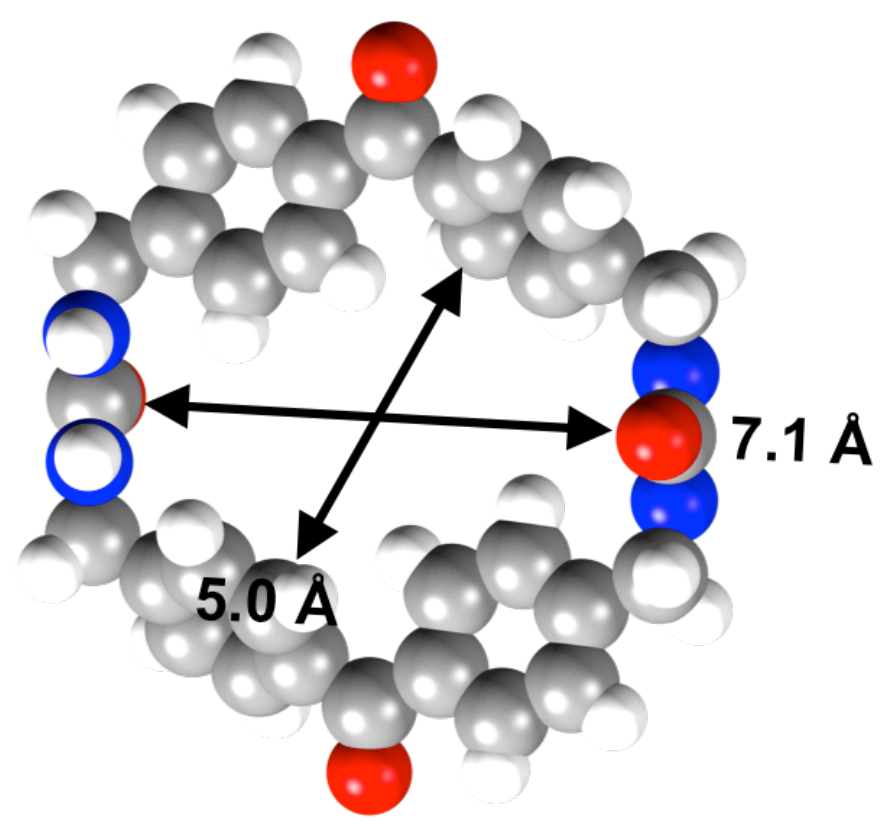

Figure S4. Space filling model of 1 obtained from the crystal structure ${ }^{2}$ showing the dimensions of the host channels measured from carbon to carbon.

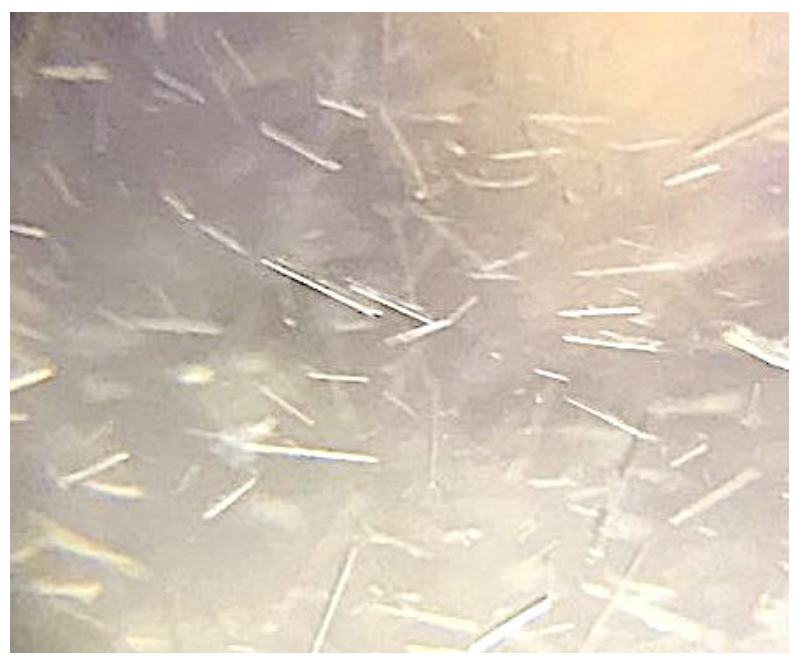

Figure S5. Self-assembly of macrocycle 1 results in the formation of needle-like crystals upon recrystallization in DMSO. Picture taken at $60 x$ magnification with a LED pocket microscope. 


\section{Decolorization of DMPO using methanol}

After the DMPO spin trapping study in chloroform the DMPO began to turn orange in color accompanied by a three line spectrum $\left(a_{N}=15 G\right)$, indicating the formation of a DMPO degradation product. Therefore, before the spin trapping study was carried out in methanol it was decolorized to remove the impurities. A traditional decolorization technique was carried out in methanol instead of water and produced similar results. ${ }^{5}$ A 200 mM stock solution of DMPO was prepared by adding DMPO $(22 \mu \mathrm{L})$ to a volumetric flask and was diluted to $1 \mathrm{~mL}$ with oxygenated methanol. Activated charcoal was added to the stock solution, which was decolorized by passing it through a $20 \mu \mathrm{m}$ syringe filter.

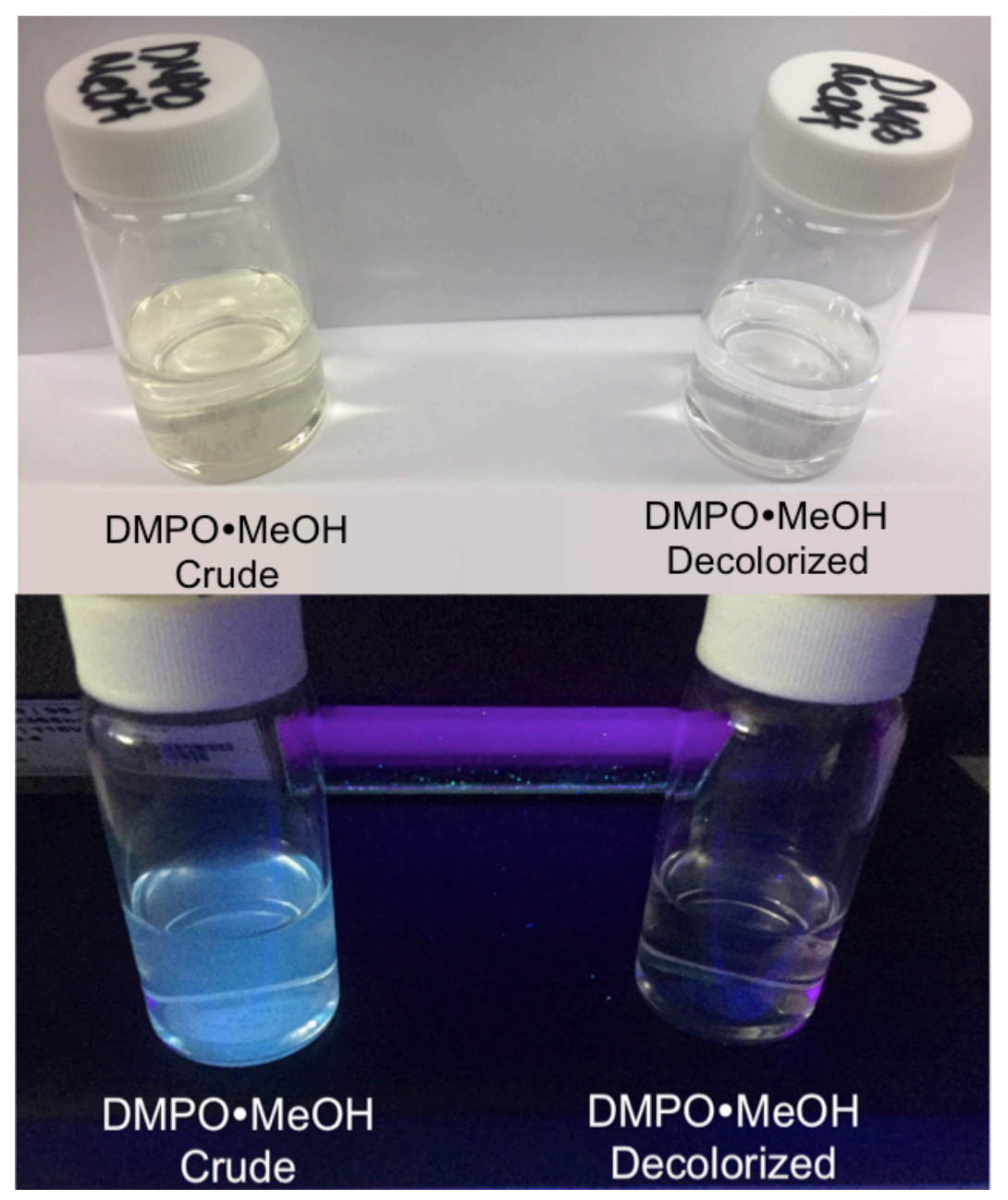

Figure S6. Decolorization of DMPO in $\mathrm{MeOH}$, (Top) Solution before and after decolorization (Bottom) Sample under UV-light before and after decolorization. 


\section{Host 1 Superoxide Spin Trapping Experiment (Methanol)}

Activated host $1(0.11 \mathrm{mg}, 0.2 \mu \mathrm{mol})$ was added to a Norell Suprasil quartz EPR tube. Next, the decolorized $200 \mathrm{mM}$ stock solution of DMPO was further diluted to $20 \mathrm{mM}$ into the EPR tube with oxygenated benzene using volumetric syringes. The EPR tube was further purged with oxygen for 2 minutes and sealed. An EPR spectrum was recorded pre-irradiation, the sample was then irradiated in a Rayonet UV reactor at $360 \mathrm{~nm}$ and EPR spectra were recorded over time.

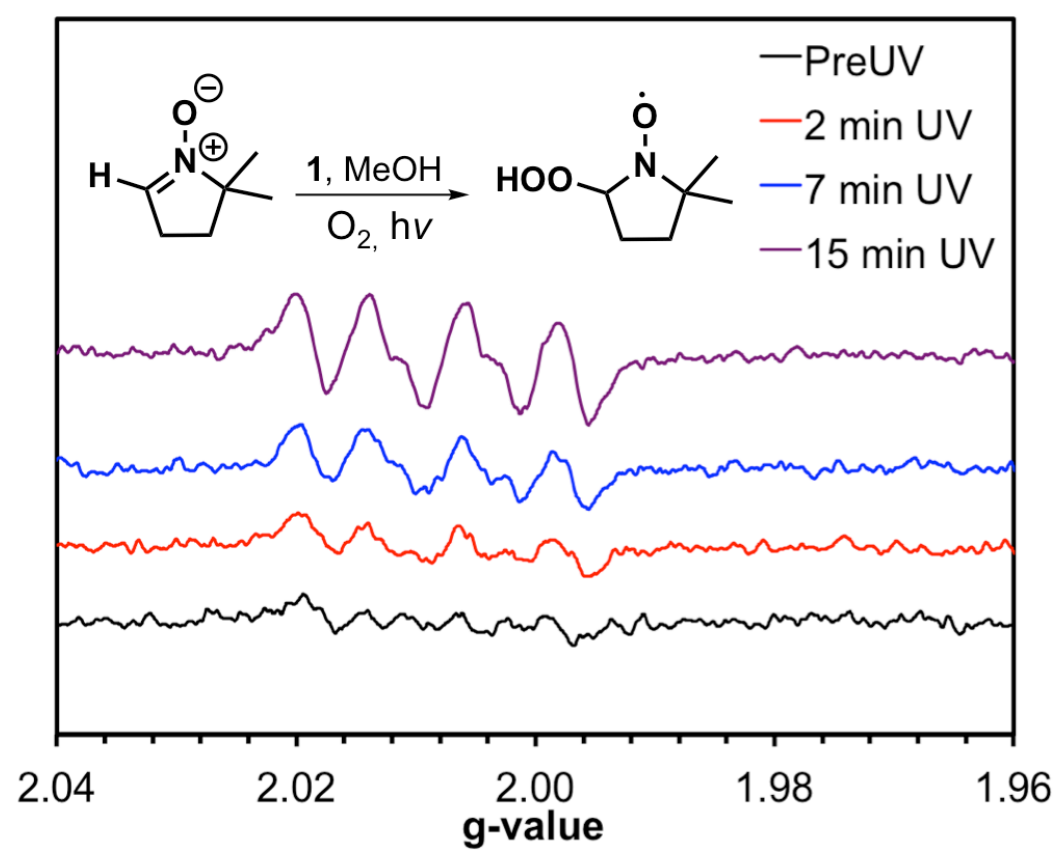

Figure S7. EPR spectra of host 1 in the presence of DMPO and methanol recorded over time of UV-irradiation. 


\section{Easy Spin simulation of DMPO adduct}

The EPR spectrum obtained by the DMPO spin trapping experiment was simulated using the MATLAB EasySpin toolbox with the "garlic" package to account for the fast motion regime at $298 \mathrm{~K}$ with a rotational correlation time of $1 \times 10^{-8}$ seconds. The simulation is consistent with the formation of a DMPO adduct with an isotropic g-value of 2.0072 (PAS Components [2.0149, 2.0057, 2.0009]) and hyperfine splitting constants of $a^{\mathrm{N}}=14.2 \mathrm{G}$ and $a^{\mathrm{H}}=9.2 \mathrm{G}$ which is in range of typical DMPO-OOH adducts.

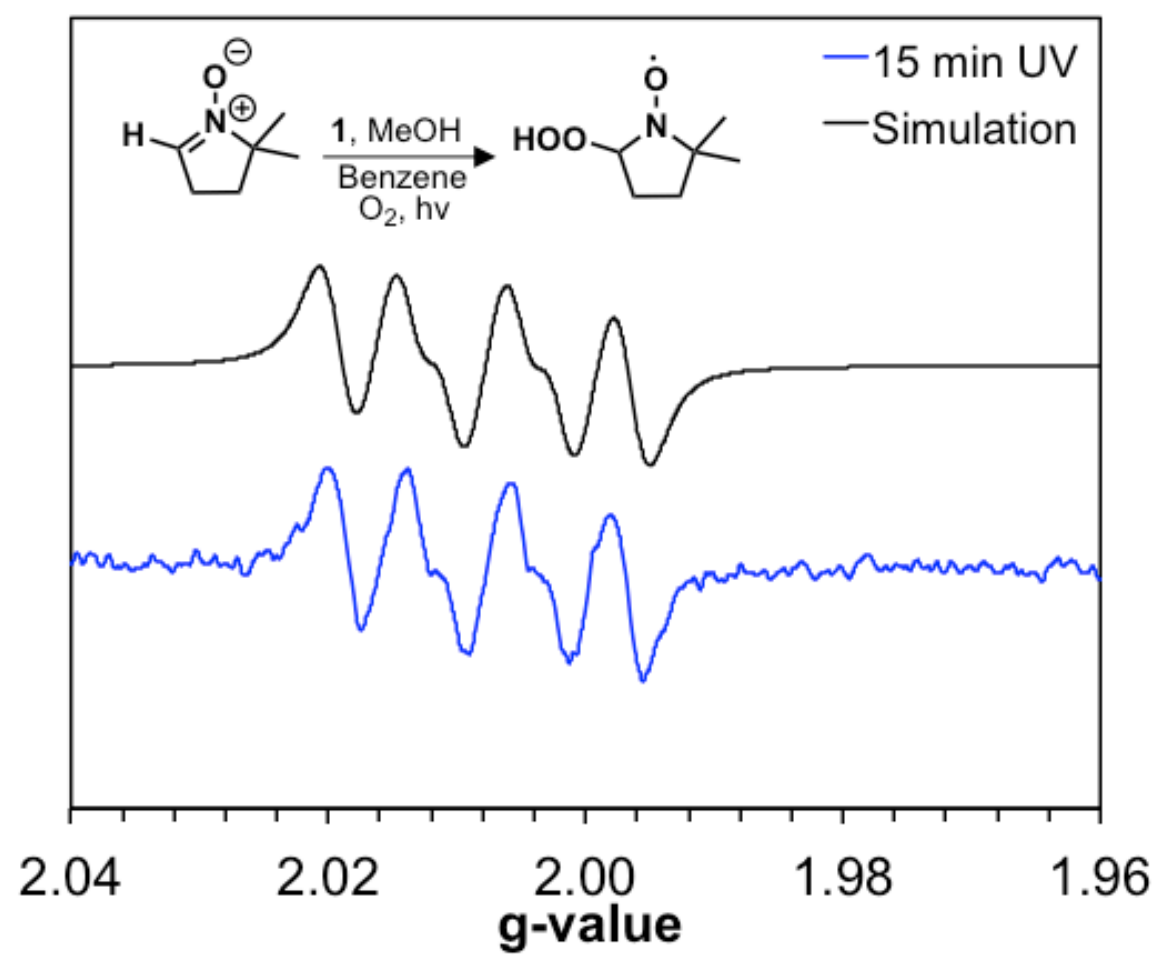

Figure S8. EPR spectral simulation (black line) of the DMPO adduct formed in the presence of host $\mathbf{1}$ and methanol recorded over time of UV-irradiation compared to the experimental spectra (blue line). 


\section{Benzophenone Superoxide Spin Trapping Experiment (Methanol)}

Benzophenone $(0.029 \mathrm{mg}, 0.16 \mu \mathrm{mol})$ was added to a Norell Suprasil quartz EPR tube. Next, the $200 \mathrm{mM}$ stock solution of DMPO was further diluted to 20 $\mathrm{mM}$ into the EPR tube with oxygenated benzene using volumetric syringes. The EPR tube was purged with oxygen for 2 minutes and sealed. An EPR spectrum was recorded pre-irradiation, the sample was then irradiated in a Rayonet UV reactor at $360 \mathrm{~nm}$ and EPR spectra were recorded over time. The EPR spectrum obtained by the DMPO spin trapping experiment was simulated using the same procedure on page S10. The simulation is consistent with the formation of a DMPO adduct with an isotropic g-value of 2.0076 (PAS Components [2.0159, $2.0060,2.0009])$ and hyperfine splitting constants of $a^{\mathrm{N}}=13.8 \mathrm{G}$ and $a^{\mathrm{H}}=9.3 \mathrm{G}$ which is in range of typical DMPO-OOH adducts.

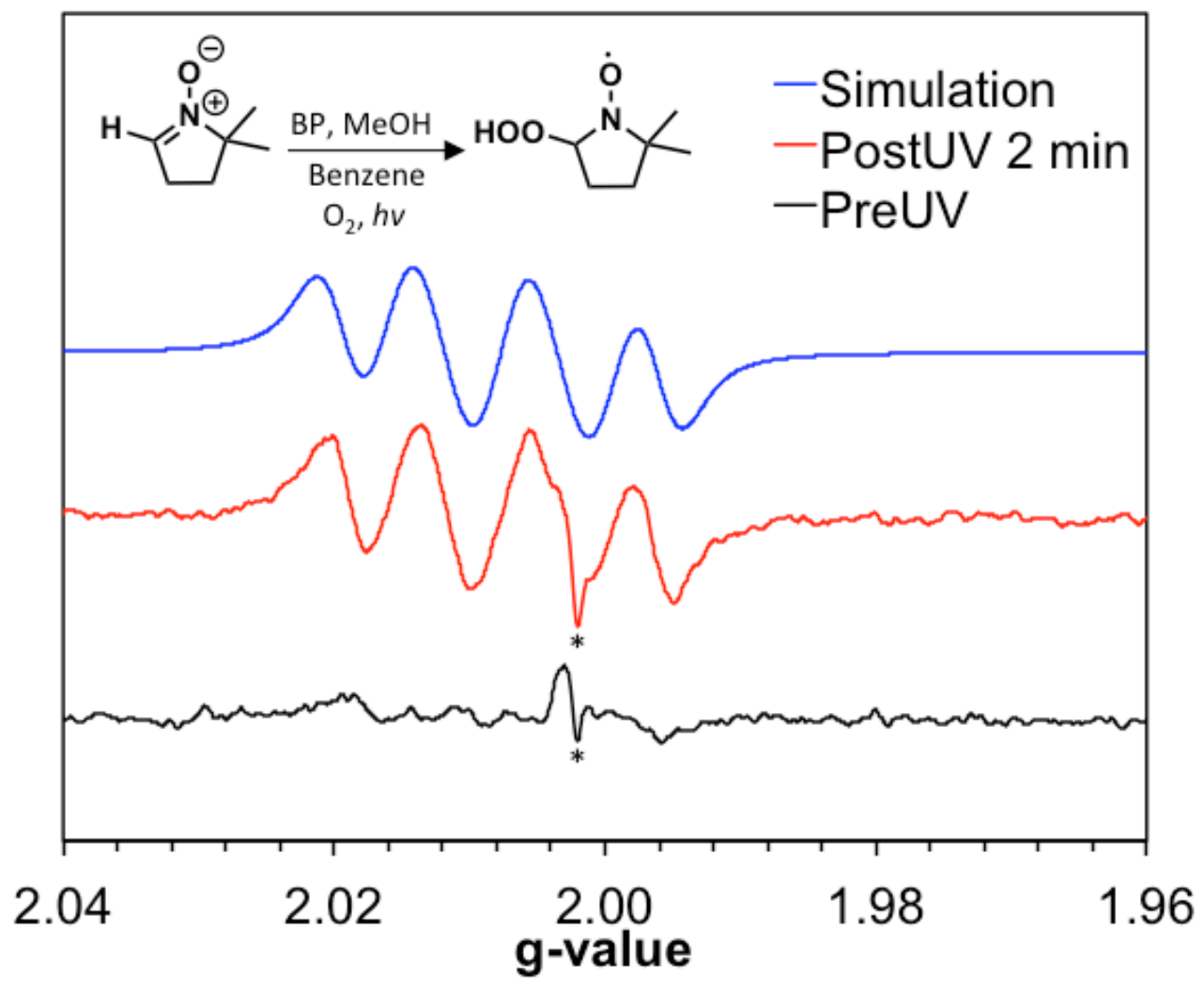

Figure S9. EPR spectral simulation (blue line) of the DMPO adduct formed in the presence of benzophenone and methanol recorded over time of UV-irradiation compared to the experimental spectra (red line). *indicates quartz EPR tube impurity at a g-value of 2.002 . 


\section{Host 1 Superoxide Spin Trapping Experiment (Chloroform)}

Host $1(1.0 \mathrm{mg}, 2.0 \mu \mathrm{mol})$ was added to borosilicate vial fitted with PTFE septum. A $0.0221 \mathrm{M}$ solution of DMPO was prepared by adding DMPO $(62 \mu \mathrm{L})$ to a $25 \mathrm{~mL}$ volumetric flask and diluted with chloroform. The DMPO solution was sparged under pure oxygen for 15 minutes, the volumetric flask was topped off with chloroform. The stock solution $(20 \mathrm{~mL})$ was added to the vial containing host 1 was added with a micro stir bar. The sample was irradiated for one hour with gentle stirring and aliquots of the DMPO solution $(0.2 \mathrm{~mL})$ were removed over time and EPR spectra were recorded. No DMPO adduct was formed after 1 hour of UV irradiation indicating that in polar aprotic solvents host 1 cannot form peroxides.

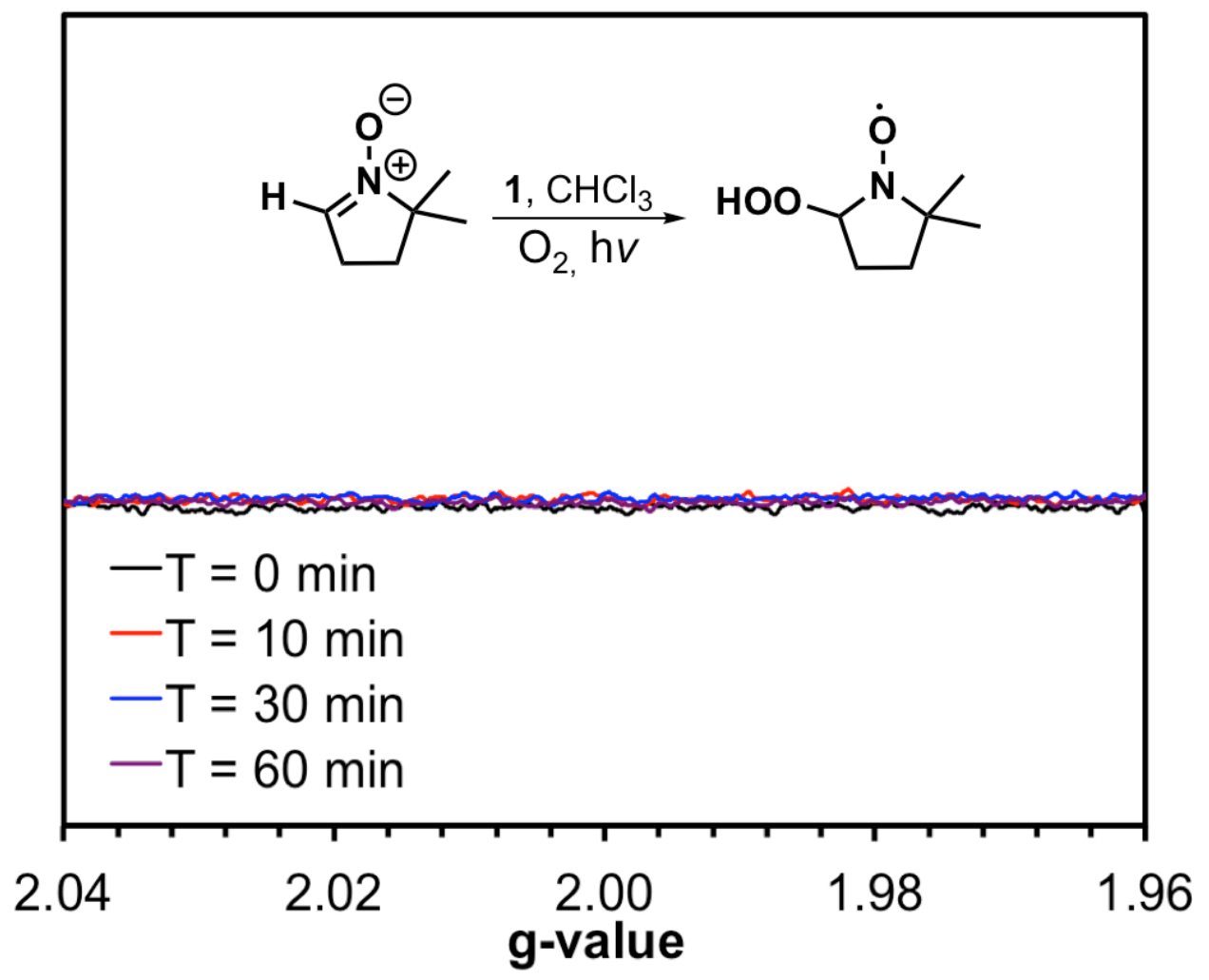

Figure S10. EPR spectra of host $1 \cdot$ DMPO in chloroform recorded over time of UV-irradiation. 


\section{Benzophenone Superoxide Spin Trapping Experiment (Chloroform)}

Benzophenone $(0.7 \mathrm{mg}, 3.8 \mu \mathrm{mol})$ was added to borosilicate vial fitted with PTFE septum. A $0.0221 \mathrm{M}$ solution of DMPO was prepared by adding DMPO $(62 \mu \mathrm{L})$ to a $25 \mathrm{~mL}$ volumetric flask and diluted with chloroform. The DMPO solution was sparged under pure oxygen for 15 minutes, the volumetric flask was topped off with chloroform. The stock solution $(20 \mathrm{~mL})$ was added to the vial containing benzophenone was added with a micro stir bar. The sample was irradiated for one hour with gentle stirring and aliquots of the DMPO solution $(0.2 \mathrm{~mL})$ were removed over time and EPR spectra were recorded. No DMPO adduct was formed after 1 hour of UV irradiation indicating that in polar aprotic solvents BP cannot form peroxides.

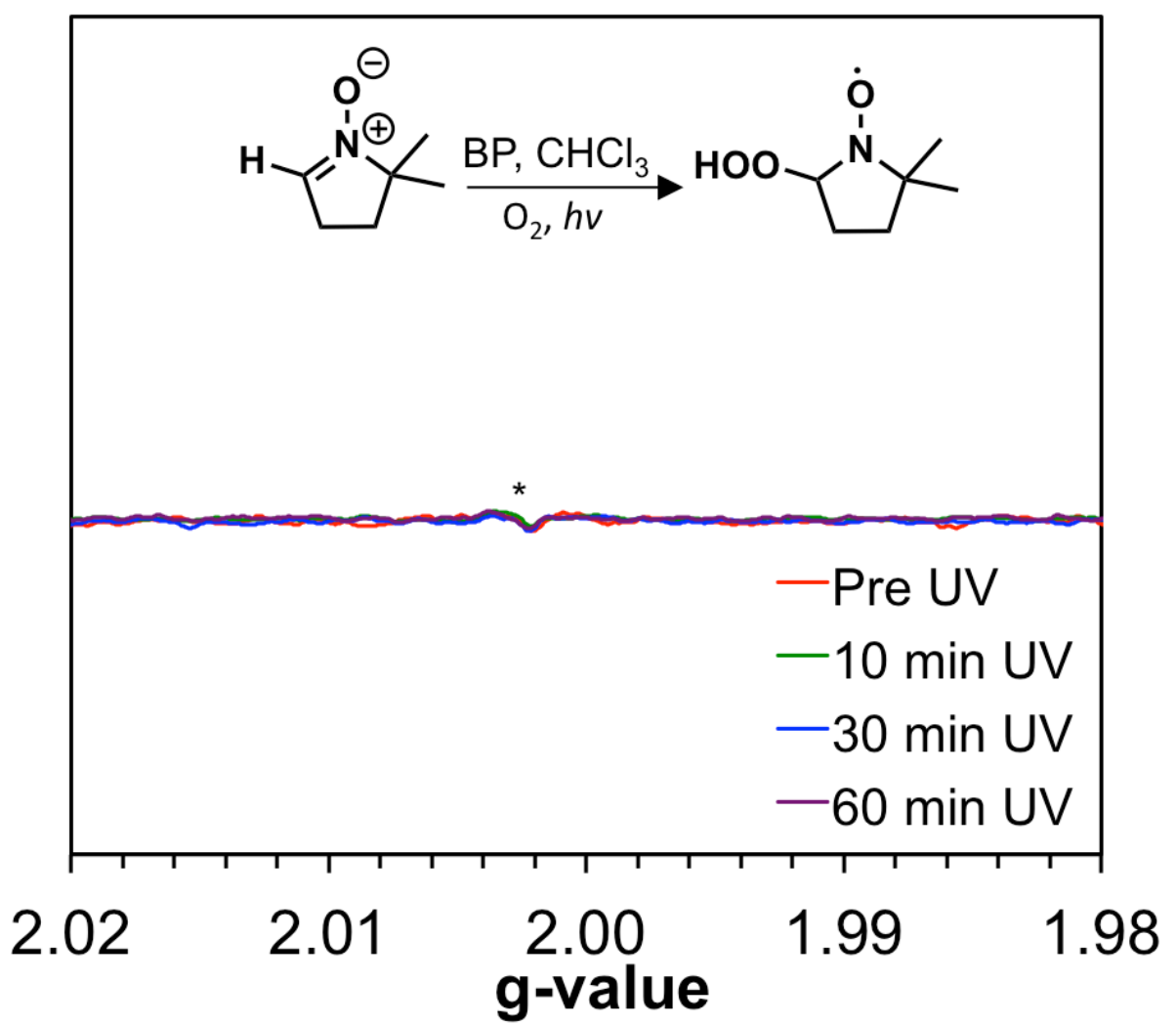

Figure S11. EPR spectra of BP•DMPO in chloroform recorded over time of UVirradiation. *indicates a quartz EPR tube impurity at a g-value of 2.002 . 
Host 1 Singlet Oxygen Trapping Experiment (Chloroform)

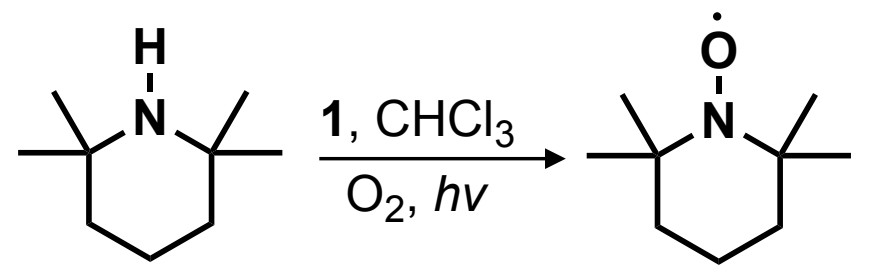

Host $1(0.1 \pm 0.02 \mathrm{mg}, 0.18 \mu \mathrm{mol})$ was added to a Norell Suprasil quartz EPR tube. A $2.9 \mathrm{mM}$ stock solution of TMP was prepared by adding TMP $(25 \mu \mathrm{L})$ to a $50 \mathrm{~mL}$ volumetric flask and was diluted with oxygenated chloroform. The stock solution $(0.2 \mathrm{~mL})$ was added to the EPR tube and sealed under oxygen. An EPR spectrum was recorded pre-irradiation and each sample was then UV irradiated and spectra were recorded over time. The sample was irradiated in a Rayonet UV reactor over time, resulting in the formation of the signature 3-line TEMPO signal.
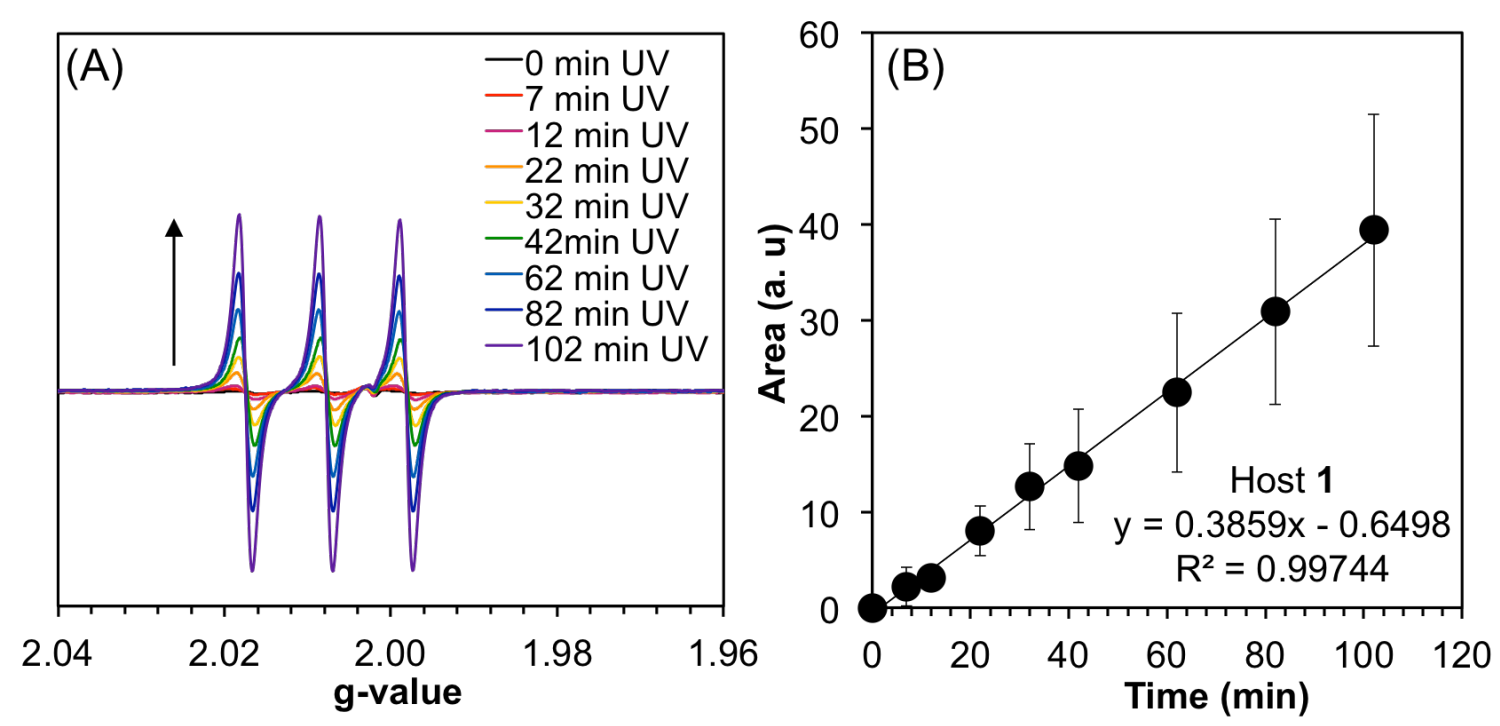

Figure S12. (A) EPR spectra of Host 1.TMP in chloroform recorded over time of UV-irradiation showing the formation of the signature TEMPO EPR spectra. (B) Area of the TEMPO EPR spectra plotted versus time of UV-irradiation. The error bars represent the standard deviation between the triplicates. 


\section{Benzophenone Singlet Oxygen Trapping Experiment (Chloroform)}<smiles>CC1(C)CCCC(C)(C(=O)OCc2ccccc2)N1O</smiles>

A $2.97 \mathrm{mM}$ stock solution of TMP was prepared by adding TMP $(25 \mu \mathrm{L})$ to a 50 $\mathrm{mL}$ volumetric flask and was diluted with oxygenated chloroform. The TMP stock solution $(20 \mathrm{~mL})$ was added to a $40 \mathrm{~mL}$ borosilicate vial with a PTFE septum followed by benzophenone $(0.7 \mathrm{mg}, 3.8 \mu \mathrm{mol})$. The solution was vortexed and oxygenated for 5 more minutes. The oxygenated solution $(0.2 \mathrm{~mL})$ was added to the EPR tube and was sealed under oxygen. An EPR spectrum was recorded pre-irradiation and each sample was then UV irradiated and spectra were recorded over time. The sample was irradiated in a Rayonet UV reactor over time, resulting in the formation of TEMPO.
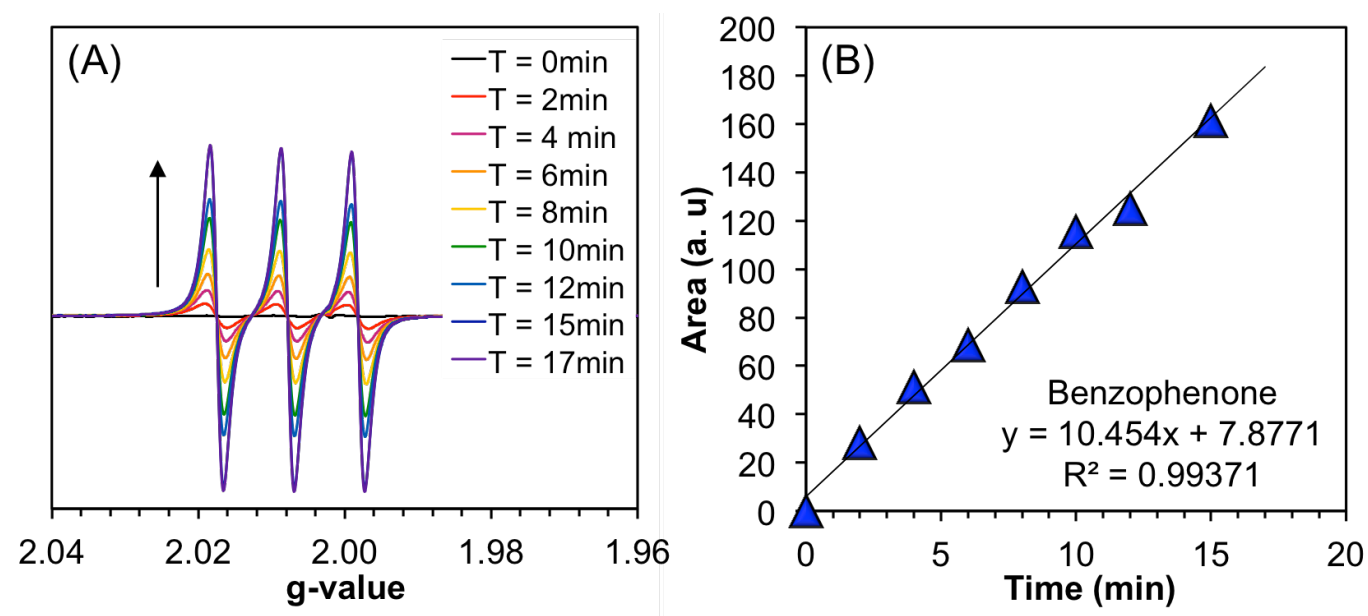

Figure S13. (A) EPR spectra of BP•TMP in chloroform recorded over time of UVirradiation showing the formation of the signature TEMPO EPR spectra. (B) Area of the TEMPO EPR spectra plotted versus time of UV-irradiation. 


\section{Perinaphthenone Singlet Oxygen Trapping Experiment (Chloroform)}<smiles>CC1(C)CCCC(C)(C(=O)ON=C(Cl)C2(C)CCCC(C)(C)N2O)N1</smiles>

A $2.97 \mathrm{mM}$ stock solution of TMP was prepared by adding TMP $(25 \mu \mathrm{L})$ to a 50 $\mathrm{mL}$ volumetric flask and was diluted with oxygenated chloroform. The TMP stock solution $(20 \mathrm{~mL})$ was added to a $40 \mathrm{~mL}$ borosilicate vial with a PTFE septum followed by benzophenone $(0.47 \mathrm{mg}, 3.9 \mu \mathrm{mol})$. The solution was vortexed and oxygenated for 5 more minutes. The oxygenated solution $(0.2 \mathrm{~mL})$ was added to the EPR tube and was sealed under oxygen. An EPR spectrum was recorded pre-irradiation and each sample was then UV irradiated and spectra were recorded over time. The sample was irradiated in a Rayonet UV reactor over time, resulting in the formation of TEMPO.
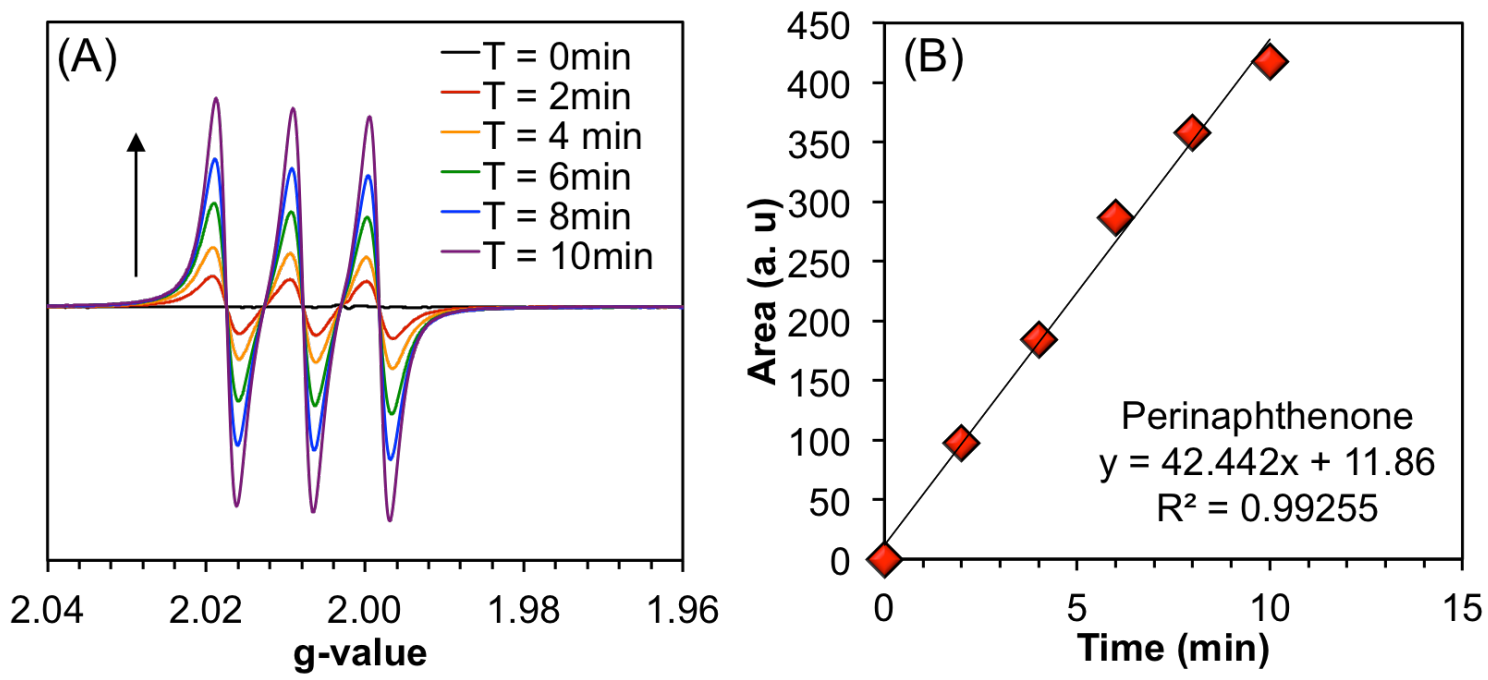

Figure S14. (A) EPR spectra of PN•TMP in chloroform recorded over time of UV-irradiation showing the formation of the signature TEMPO EPR spectra. (B) Area of the TEMPO EPR spectra plotted versus time of UV-irradiation. 


\section{Singlet Oxygen Quantum Yield Determination - EPR}

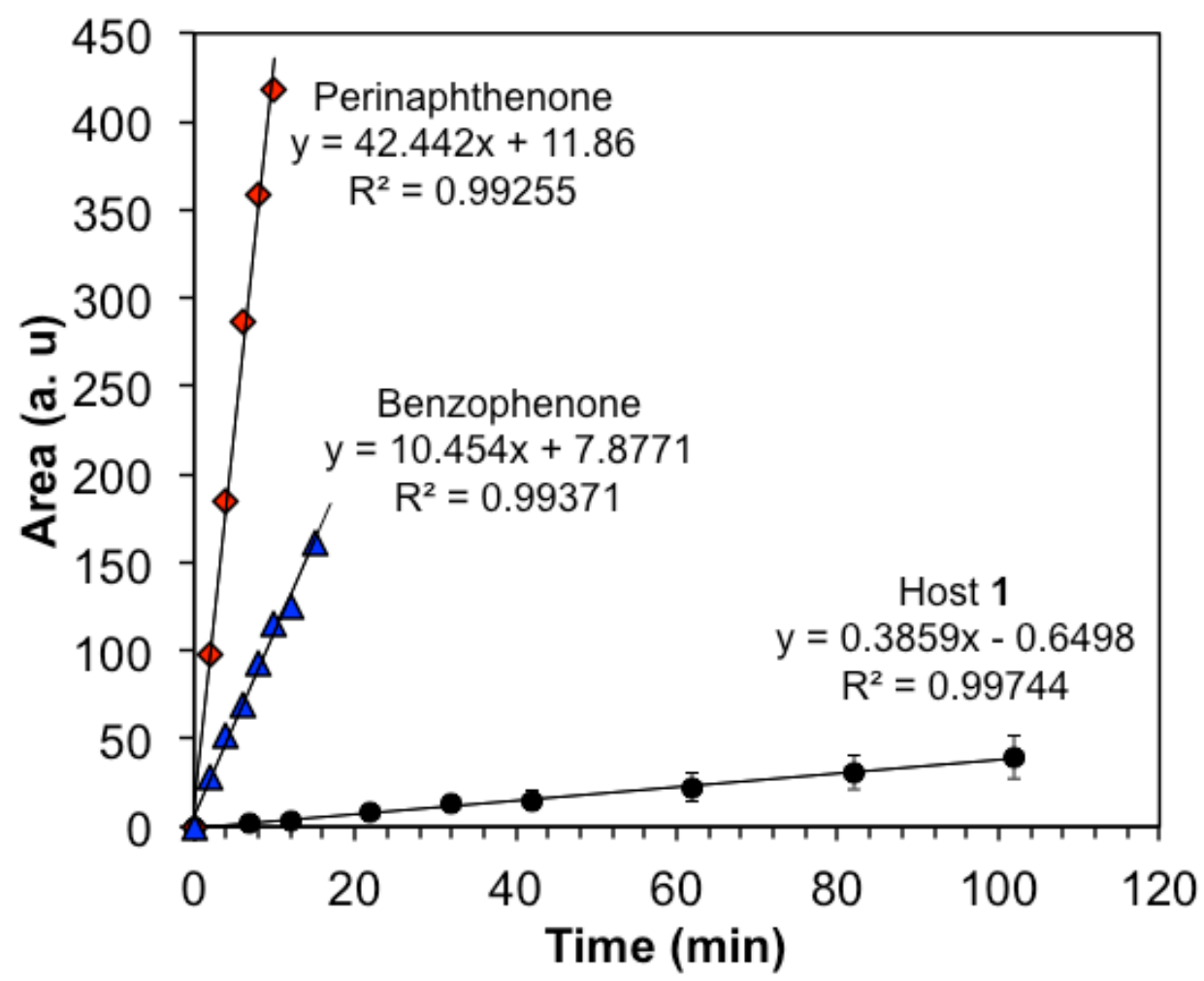

Figure S15. Comparison of area obtained in the formation of TEMPO for perinaphthenone, benzophenone, and host 1 spectra plotted versus time of UVirradiation, the slopes were used to determine singlet oxygen quantum yield. Perinaphthenone was used as the reference.

$$
\begin{gathered}
\Phi\left[{ }^{1} \mathrm{O}_{2}\right]^{\text {host } 1}=\Phi\left[{ }^{1} \mathrm{O}_{2}\right]^{\mathrm{PN}}\left(\mathrm{m}^{\text {host } 1} / \mathrm{m}^{\mathrm{PN}}\right) \\
\Phi\left[{ }^{1} \mathrm{O}_{2}\right]^{\text {host } 1}=1 \% \\
\text { Where, } \mathrm{m}^{\text {host } 1}=\text { slope of host plot }=0.3859 \\
\mathrm{~m}^{\mathrm{PN}}=\text { slope of reference plot }=44.442 \\
\Phi\left[{ }^{1} \mathrm{O}_{2}\right]^{\mathrm{PN}}=\text { quantum yield of reference }=0.97 \\
\Phi\left[{ }^{1} \mathrm{O}_{2}\right]^{\text {host } 1}=\text { quantum yield of host } 1
\end{gathered}
$$




\section{Singlet Oxygen Quantum Yield Determination via UV-vis}<smiles>Cc1ccc(Cl)c2cc([N+](=O)[O-])ccc12</smiles>

Activated host $1(1.1 \mathrm{mg})$ was added to a stock solution of 1,4dimethylnaphthalene in $\mathrm{CHCl}_{3}(16 \mathrm{~mL}$ of a $2.86 \mathrm{mM}$ soln) in a vial with septum and purged under an $\mathrm{O}_{2}$ balloon for 10 minutes. The sample was UV-irradiated in a Rayonet reactor with gentle stirring in a room temperature water bath for 70 min. Samples $(0.1 \mathrm{~mL})$ were removed at 10 to 20 minute time intervals, diluted with $\mathrm{CHCl}_{3}(1.9 \mathrm{~mL})$ and monitored by UV-vis spectroscopy. Extra care was taken to ensure none of the host was removed from the reaction flask.
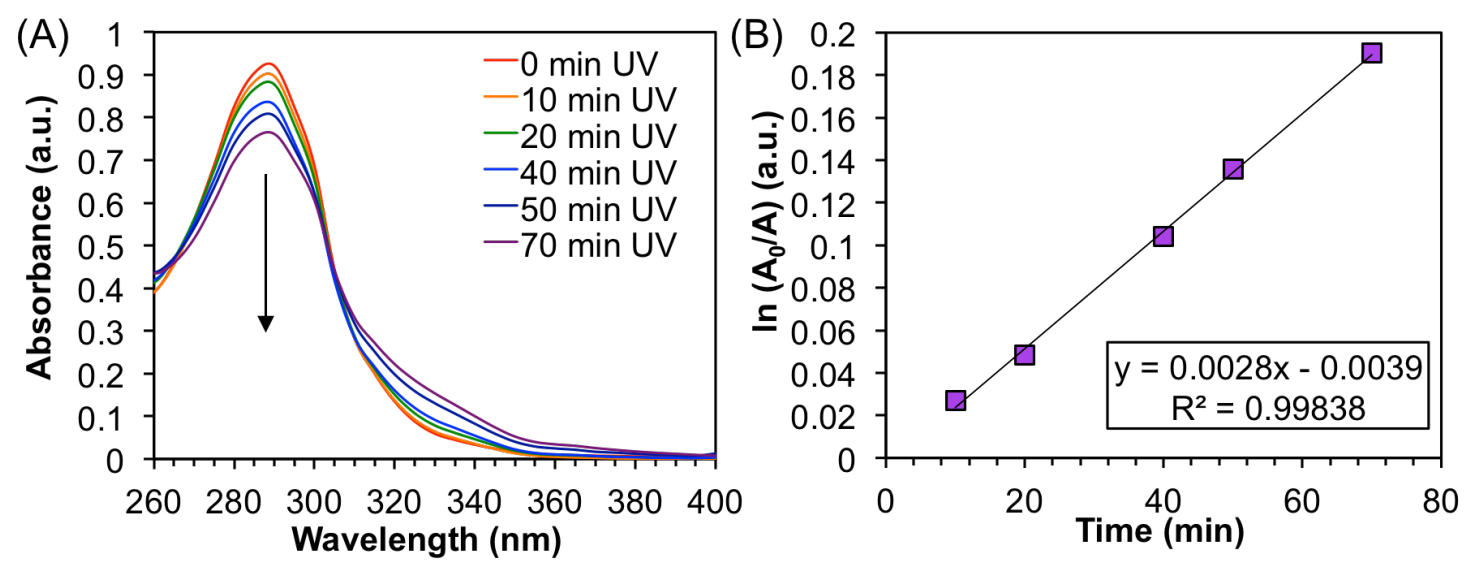

Figure S16. Singlet oxygen quantum yield determination of host 1 via UV-vis (A) Plot of DMN absorbance spectra over time of UV-irradiation. (B) Plot of DMN degradation versus time of UV- irradiation in presence of host 1. 


\section{Singlet Oxygen Quantum Yield Determination via UV-vis}<smiles>Cc1ccc(C)c2ccccc12</smiles>

Methylene blue $(0.6 \mathrm{mg})$ was added to a stock solution of 1,4dimethylnaphthalene in $\mathrm{CHCl}_{3}$ (16 mL of a $2.86 \mathrm{mM}$ sol'n) in a vial with septum and purged under an $\mathrm{O}_{2}$ balloon for 10 minutes. The sample was irradiated using a CFL 14W light bulb under gentle stirring in a room temperature water bath for $40 \mathrm{~min}$. Samples $(0.1 \mathrm{~mL})$ were removed at 10 -minute time intervals, diluted with $\mathrm{CHCl}_{3}(1.9 \mathrm{~mL})$ and monitored by UV-vis spectroscopy.
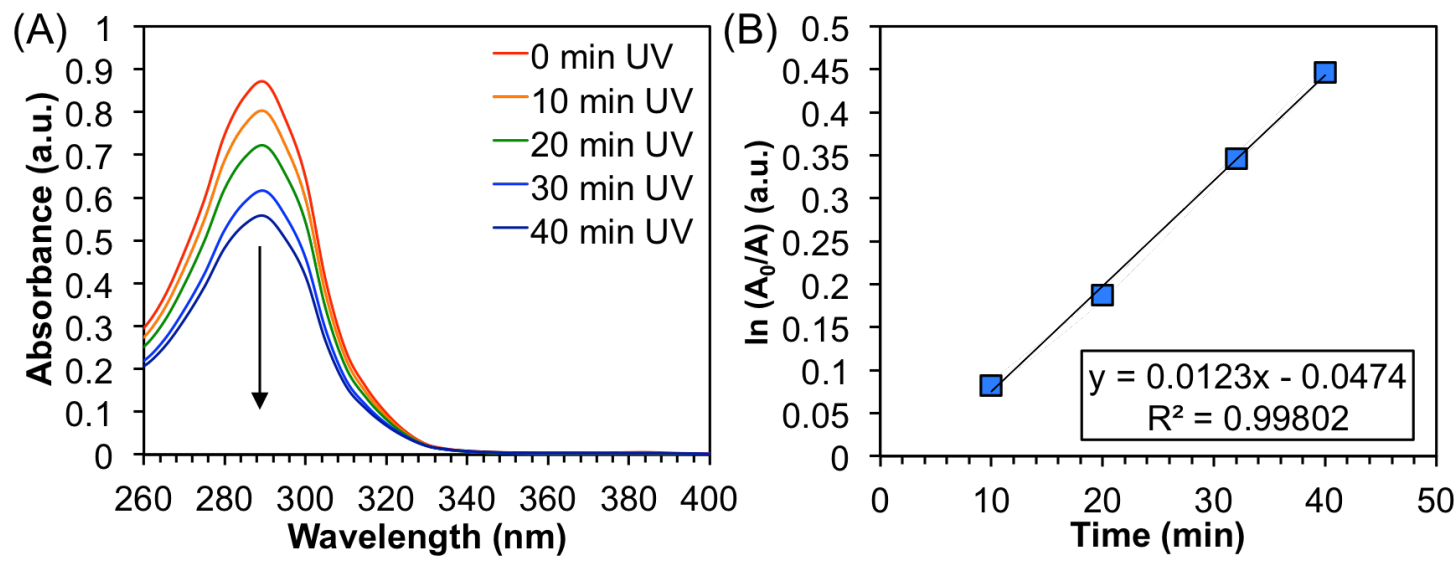

Figure S17. Absorption data for DMN quenching experiments sensitized by methylene blue. (A) Plot of DMN absorbance spectra over time of UV-irradiation. (B) Plot of DMN degradation versus time of UV- irradiation in presence of the reference methylene blue. 


\section{Singlet Oxygen Quantum Yield Determination via UV-vis}

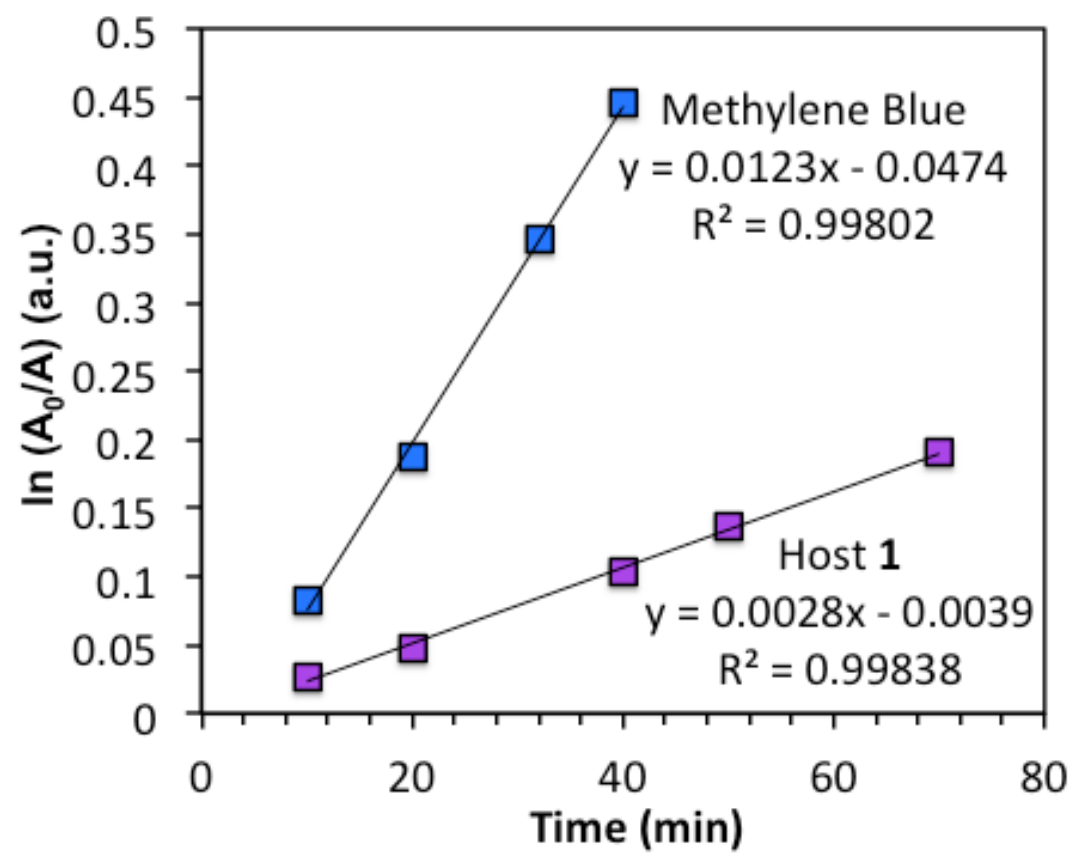

Figure S18. Comparison of absorptions obtained in 1,4-dimethylnaphthalene quenching experiment for methylene blue and host 1 spectra plotted versus time of UV-irradiation. The slopes were used to determine singlet oxygen quantum yield. Methylene blue was used as the reference.

$$
\begin{gathered}
\Phi\left[{ }^{1} \mathrm{O}_{2}\right]^{\text {host } 1}=\Phi\left[{ }^{1} \mathrm{O}_{2}\right]^{\mathrm{MB}}\left(\mathrm{m}^{\text {host } 1} / \mathrm{m}^{\mathrm{MB}}\right) \\
\Phi\left[{ }^{1} \mathrm{O}_{2}\right]^{\text {host } 1}=12 \% \\
\text { Where, } \mathrm{m}^{\text {host } 1}=\text { slope of host plot }=0.0028 \\
\mathrm{M}^{\mathrm{MB}}=\text { slope of reference plot }=0.0123 \\
\Phi\left[{ }^{1} \mathrm{O}_{2}\right]^{\mathrm{MB}}=\text { quantum yield of reference }=0.52 \\
\Phi\left[{ }^{1} \mathrm{O}_{2}\right]^{\text {host } 1}=\text { quantum yield of host } 1
\end{gathered}
$$


The host:guest ratio was determined using TGA using the following equation:

$$
\text { Host: Guest }=\frac{\text { mols of host }}{\text { mols of guest }}
$$
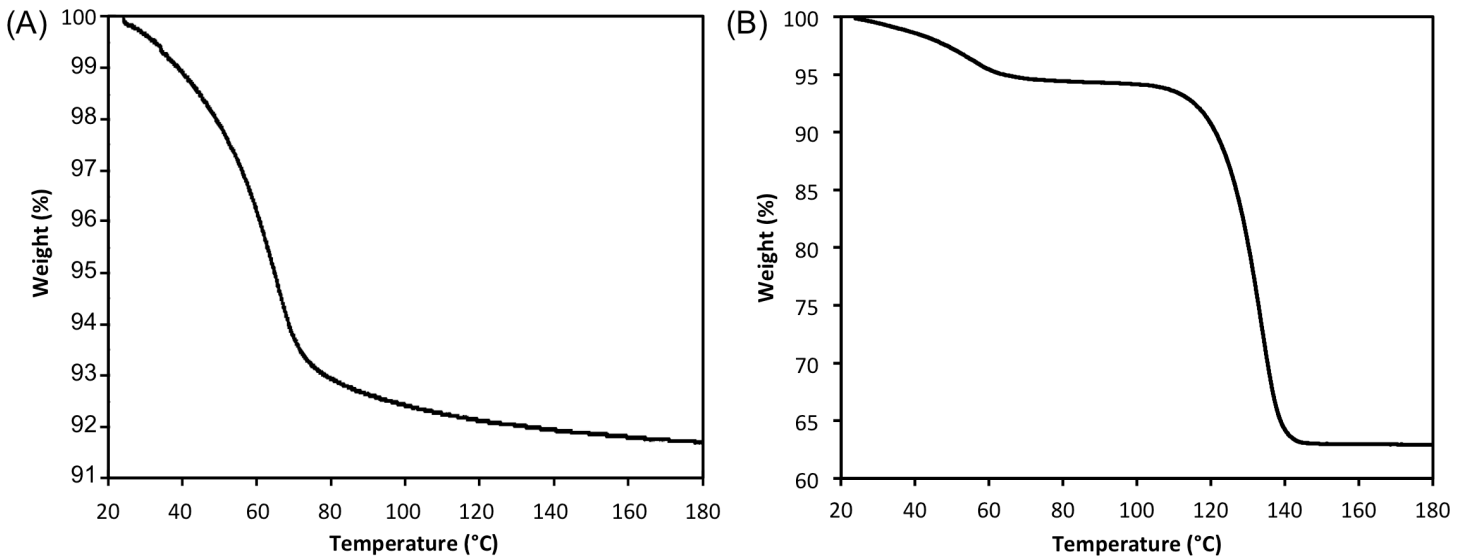

Figure S19. Thermogravimetric Analysis (TGA) plots were used to determine how well different guest load into host 1 . The TGA was heated at a ramp rate of 4 ${ }^{\circ} \mathrm{C} / \mathrm{min}$ to $180^{\circ} \mathrm{C}$ and show the removal of guest molecules from the host. Most guests displayed 1-step desorption curves. (A) TGA of the host $\mathbf{1 \cdot 2}$ complex shows a one-step desorption with a weight loss of $8.2 \%$ from $20-80^{\circ} \mathrm{C}$ which is attributed to the loss of the alkene from the host channels. The host:guest stoichiometry was calculated from the weight loss using Eq'n 3 to be 2:1. (B) TGA of the host 1.DMPO complex exhibited a two-step desorption curve from 20 to $140^{\circ} \mathrm{C}$ with a total weight loss of $37.1 \%$. NMR suggests that the first desorption step accounts for the loss of water. The second step is attributed to the loss of DMPO which accounted for $31.3 \%$ of the weight loss, from which the host:guest stoichiometry was calculated to be 1:2. The following guests loaded were loaded: dimethylsulfoxide (DMSO), 1-methyl-1-cyclohexene (2), 2,2,6,6-tetramethyl piperidine (TMP), 5,5-dimethyl-1-pyrroline N-oxide (DMPO), pyridine, N,Ndimethylaniline(DMA), and N,N,N',N'-tetramethylethylenediamine (TMEDA).

Table S1. Host:Guest ratios calculated from TGA desorption curves. ${ }^{a}$

\begin{tabular}{|c|c|c|c|c|c|}
\hline Entry & Sample & $\begin{array}{c}\text { Desorption } \\
\text { Curve }\end{array}$ & $\begin{array}{c}\text { Temperature } \\
\text { Range }\left({ }^{\circ} \mathrm{C}\right) \\
\end{array}$ & $\begin{array}{c}\% \text { Weight } \\
\text { Loss }\end{array}$ & Host:Guest \\
\hline 1 & 1•DMSO & 1-step & $45-145^{\circ} \mathrm{C}$ & $12 \%$ & $1: 1$ \\
\hline 2 & $1 \cdot 2$ & 1-step & $20-80^{\circ} \mathrm{C}$ & $8.2 \%$ & $2: 1$ \\
\hline 3 & 1•TMP & $\mathrm{N} / \mathrm{A}$ & $\mathrm{N} / \mathrm{A}$ & $\mathrm{N} / \mathrm{A}$ & $1: 0$ \\
\hline 4 & 1•DMPO & 2-step & $20-140^{\circ} \mathrm{C}$ & $31.3 \%$ & $1: 2$ \\
\hline 5 & 1•pyridine & 1-step & $20-160^{\circ} \mathrm{C}$ & $6.6 \%$ & $2: 1$ \\
\hline 6 & $1 \cdot \mathrm{DMA}^{\mathrm{b}}$ & 2-step & $20-180^{\circ} \mathrm{C}$ & $11.7 \%$ & $2: 1$ \\
\hline 7 & 1•TMEDA & 1-step & $20-128^{\circ} \mathrm{C}$ & $8.2 \%$ & $2.5: 1$ \\
\hline
\end{tabular}

${ }^{\text {a }}$ TGA samples heated at a ramp rate of $4{ }^{\circ} \mathrm{C} / \mathrm{min}$ to $180{ }^{\circ} \mathrm{C}$ unless otherwise specified. ${ }^{\mathrm{b}} \mathrm{Heated}$ to $200^{\circ} \mathrm{C}$. 


\section{Photooxidation Procedures}

Recrystallized needles of 1 were activated using TGA before any photooxidations were carried out.

\section{Catalytic Reactions:}

To borosilicate vials, emptied host $(2.0 \pm 0.1 \mathrm{mg})$ was added followed by oxygenated solvents that were purged for 15 minutes under pure oxygen (benzene or chloroform, $1.0 \mathrm{~mL}$ ). Next, 1-methyl-1-cyclohexene $(2.5 \mu \mathrm{L})$ was added to each vial, which were sealed under oxygen and parafilmed. The samples were irradiated in a Rayonet reactor with gentle agitation. Following irradiation samples were tested for peroxides and quenched with triphenylphosphine. The samples were diluted with dichloromethane and examined with GC-MS.

\section{Solid-state Reactions:}

1-Methyl-1-cyclohexene was allowed to vapor load into host $1(16.0 \pm 1 \mathrm{mg})$ for at least 24 hours. Next, each sample was cooled in a dry-ice/acetone bath and purged under pure oxygen for 15 minutes and parafilmed. The samples were irradiated for 5 hours with a Hanovia 450W medium pressure mercury arc lamp cooled in a quartz emersion well at $0{ }^{\circ} \mathrm{C}$. Following irradiation, samples were extracted into triphenylphosphine-saturated tetrahydrofuran with sonication. The samples were diluted with dichloromethane and examined with GC-MS. 


\section{Host 1 photoxidation of 1-methyl-1-cyclohexene in chloroform}
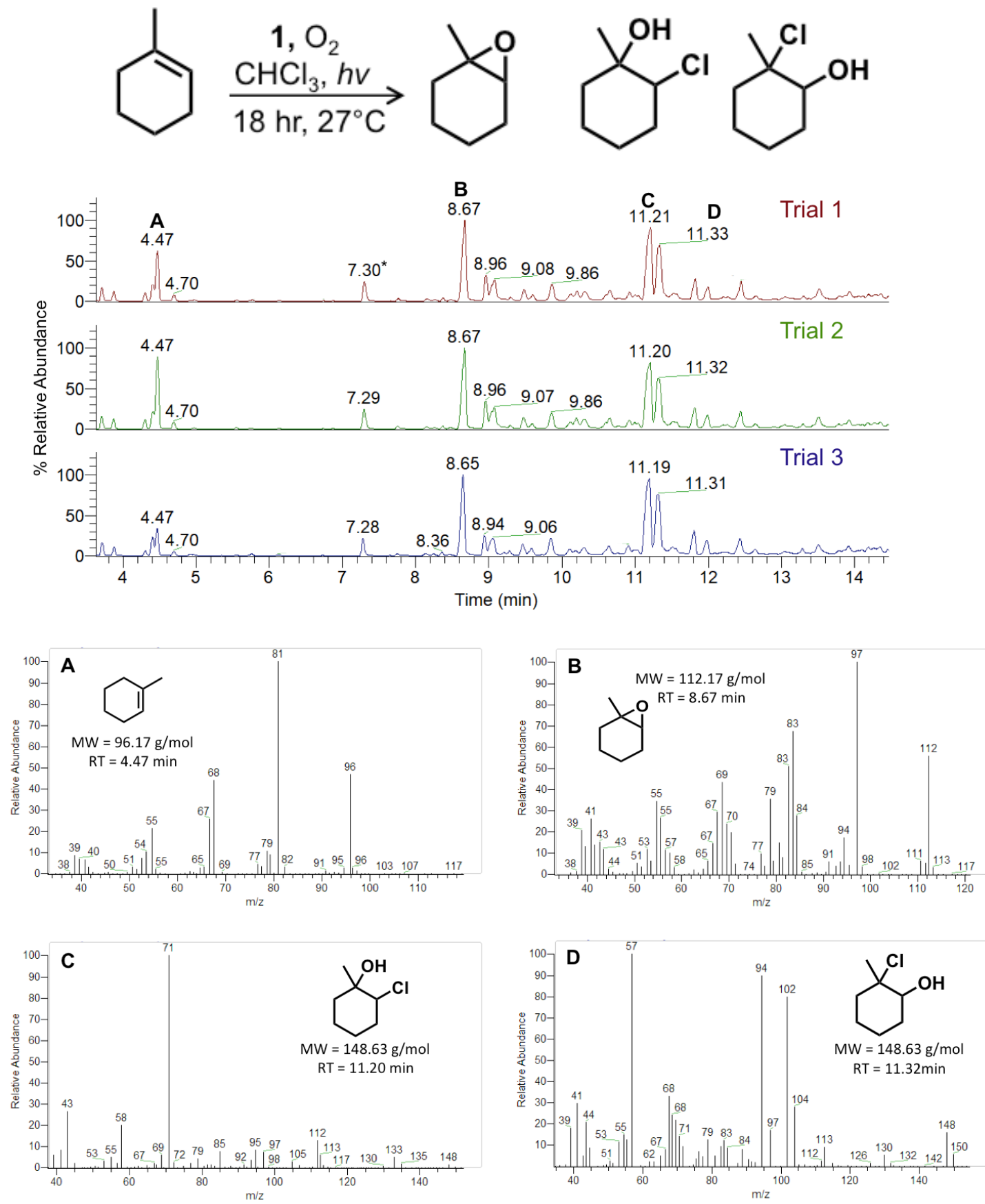

Figure S20. GC-MS data for the photooxidation of 2 sensitized by host 1 and carried out in chloroform. Top: GC-trace of products extracted diluted into dichloromethane (triplicates). Bottom: mass spectra of key materials: (A) starting material 2, (B) epoxide 6, (C) chlorohydrin $7^{6}$, and (D) chlorohydrin $\mathbf{8}^{6}$. ${ }^{*} 1$ Methylcyclohex-2-en-1-ol (5) was also formed, but not as a major product, and co-elutes with cyclohexanone. 


\section{Host 1 photoxidation of 1-methyl-1-cyclohexene in the solid state}<smiles>CC1=CCCCC1</smiles><smiles>CC(C)(O)C#CC1CCC=CC1(C)O</smiles><smiles>CC1=CC(=O)CCC1</smiles><smiles>CC1(O)CCCCC1O</smiles>
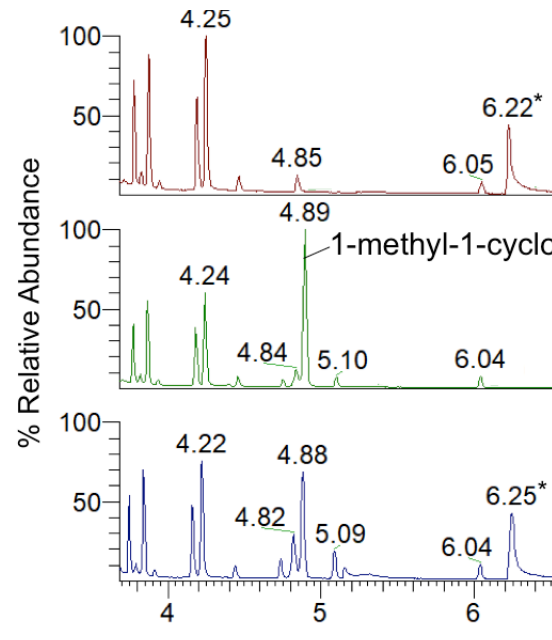

THF Blank
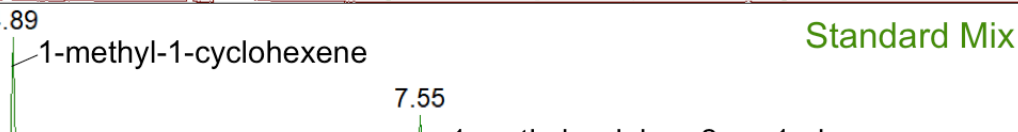

1-methylcyclohex-2-en-1-ol

$7.57 \quad$ Reaction Mixture

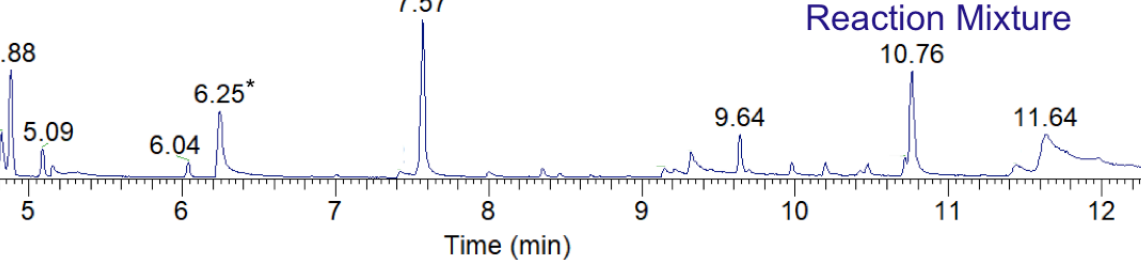

Figure S21. GC trace of 2 photooxidation carried out as a solid-state complex within 1 as the photosensitizer. Top: THF Blank. Middle: 1-methyl-1-cyclohexene (2) and 1-methyl-cyclohex-2-en-1-ol (5) standards. Bottom: the reaction mixture of extracted products. ${ }^{*}$ DMSO contamination. 

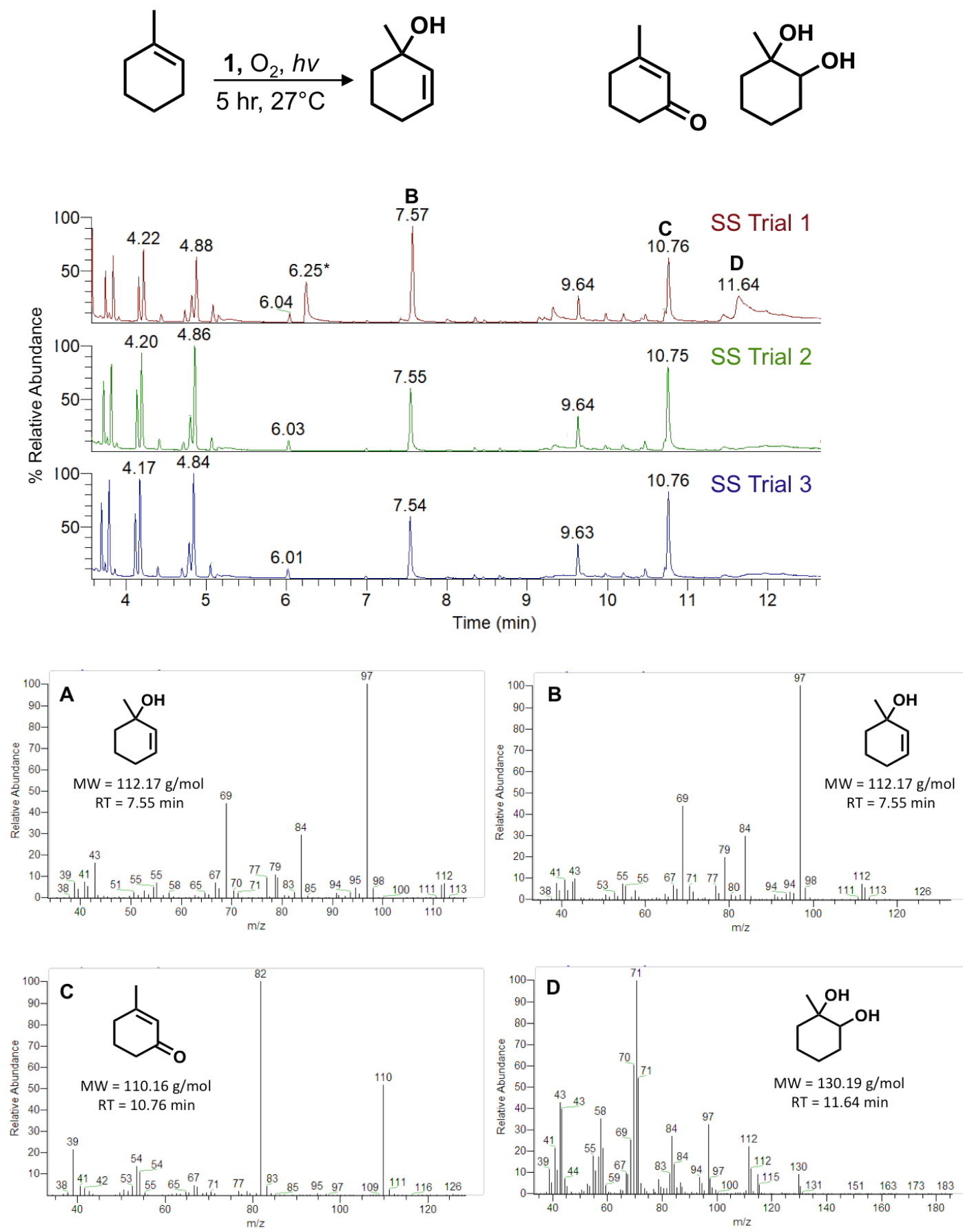

Figure S22. GC-MS data of 2 photooxidation carried out as a solid-state complex within 1 as the photosensitizer. Top: GC-trace of products extracted into THF. Bottom: mass spectra of key materials; (A) standard of tertiary alcohol 5, (B) tertiary alcohol 5, (C) enone 10, and (D) diol 9. 
Host 1 photoxidation of 1-methyl-1-cyclohexene in benzene

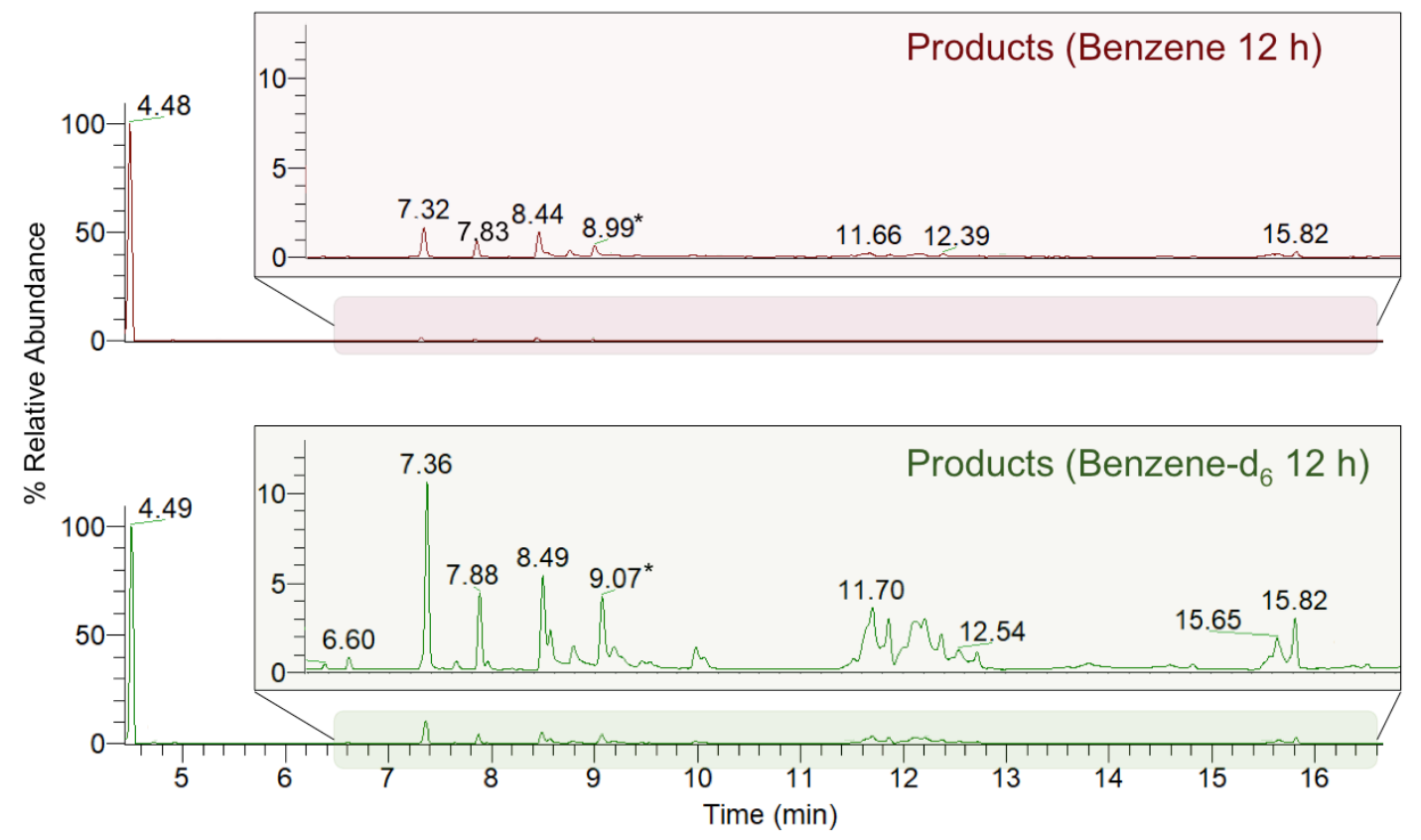

Figure S23. GC-MS traces of 2 photooxidation in the benzene (top) and benzene- $\delta_{6}$ (bottom) mediated by 1 . Due to lower conversion of starting material, a zoomed-in view of the products region of each chromatogram is also shown. ${ }^{*}$ Oxidation product of solvent: phenol (top) and phenol- $\delta_{6}$ (bottom) 


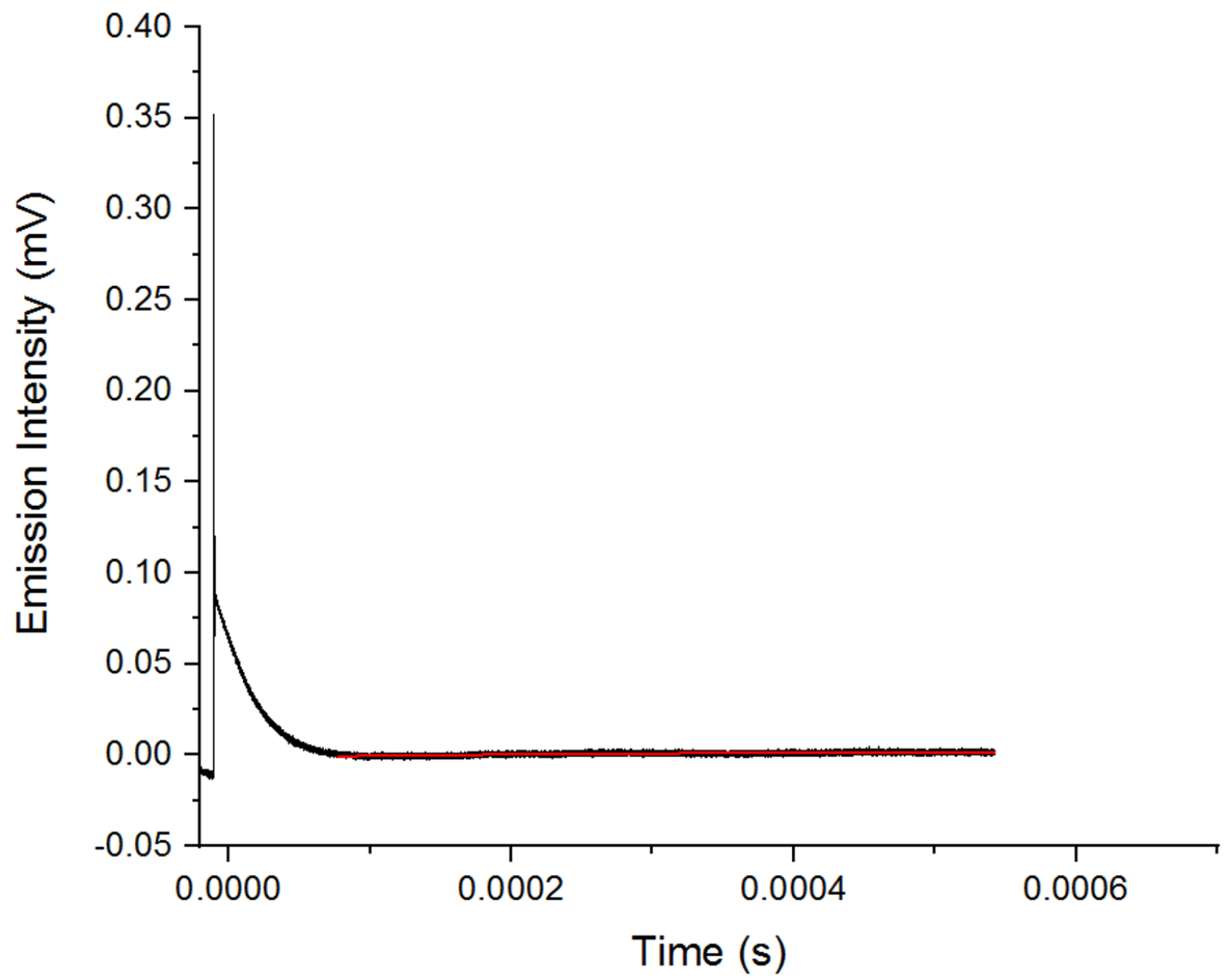

Figure S24. Airborne Singlet oxygen decay curve at the outer surface of host 1. Experimental data (black line) and fitting of the airborne singlet oxygen decay component (red line) are shown. $\tau_{\Delta \text { airborne }}$ was determined by a non-linear least squares curve-fitting procedure in Origin software. All loaded quenchers (pyridine, DMSO, DMA and TMEDA) exhibited similar $\tau_{\Delta \text { airborne }}$ lifetimes. 


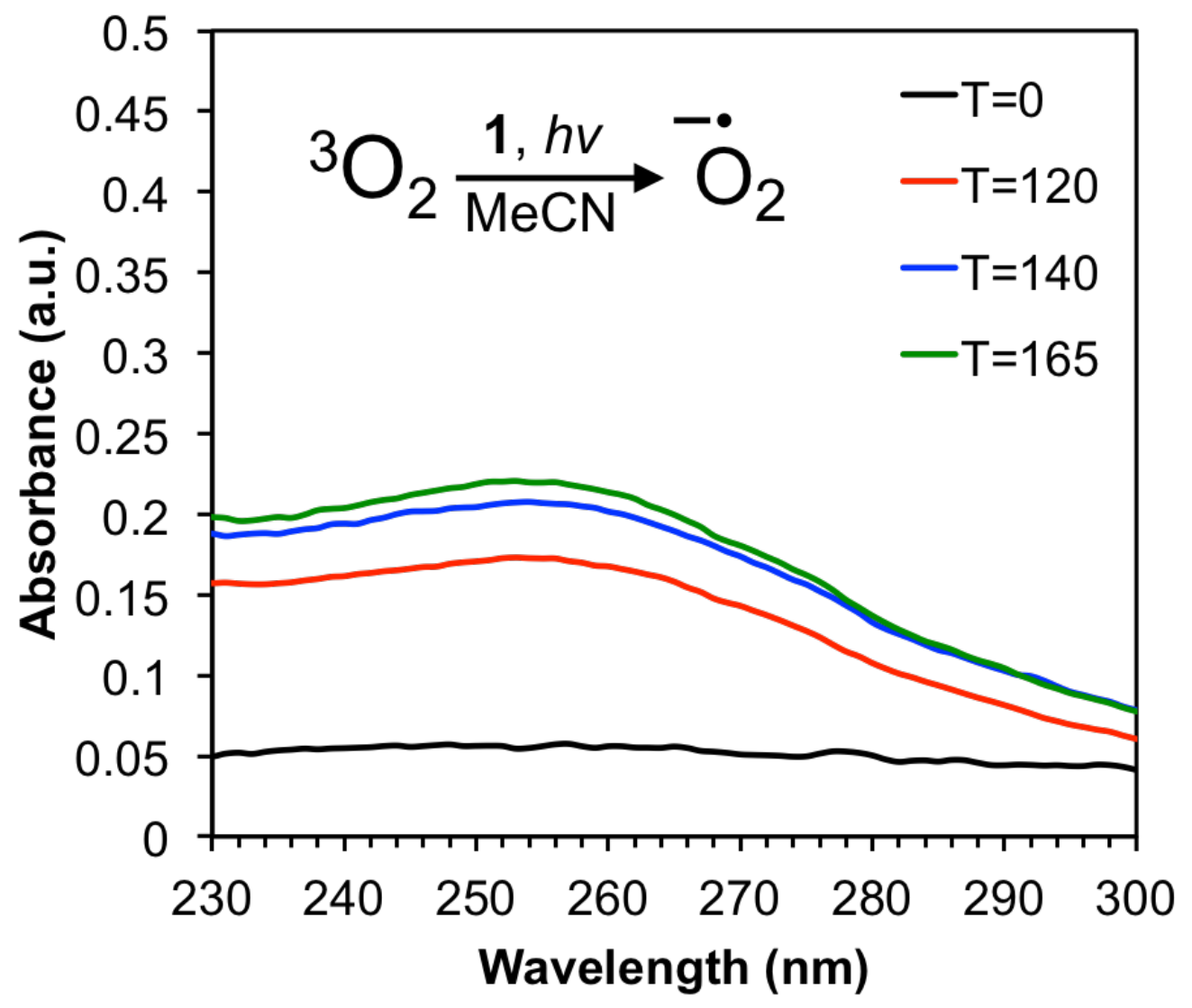

Figure S25. Direct detection of superoxide in acetonitrile $\left(\lambda_{\max }\right.$ at $\left.255 \mathrm{~nm}\right)$. Empty host 1 (8 $\mathrm{mg}$ ) was added to a cuvette containing oxygenated acetonitrile $(2 \mathrm{~mL})$ and the cuvette was sealed under oxygen. UV-visible spectroscopy was recorded pre-irradiation and over time of irradiation. The host sinks to the bottom of the cuvette in acetonitrile, thus the sample was agitated to remain suspended during irradiation. Measurements were recorded when host was settled at the bottom of the cuvette. 


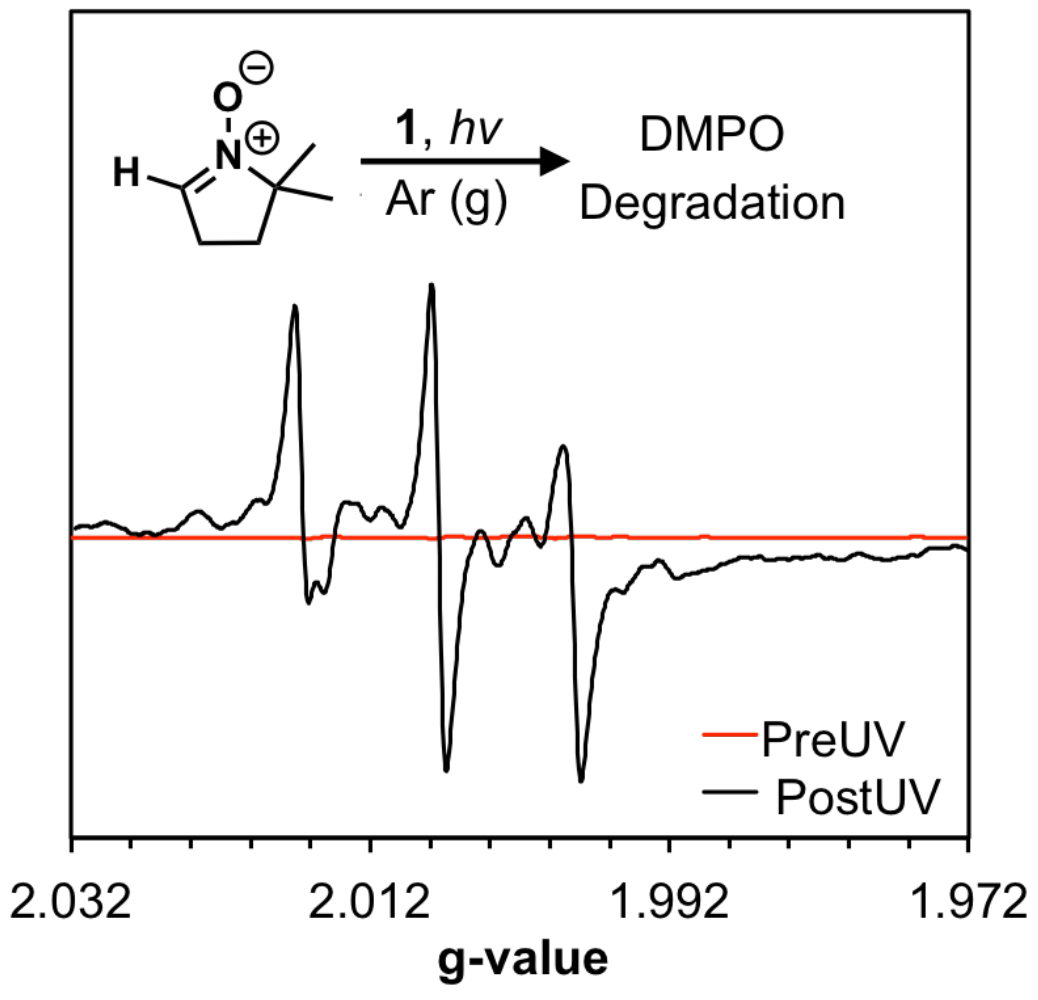

Figure 26. EPR spin trapping study $1 \cdot$ DMPO complex. A $1 \mathrm{mM}$ solution of DMPO in cyclohexane was prepared. Emptied host $1(5 \mathrm{mg})$ was added and left to soak overnight under and inert atmosphere. The solution was filtered; the crystals were washed with cyclohexane, and added to an EPR tube, which was sealed under Argon. EPR was recorded pre and post UV 1 hour. The sample was irradiated at $0^{\circ} \mathrm{C}$. 


\section{References}

1. Bartusik, D.; Aebisher, D.; Lyons, A. M.; Greer, A. Bacterial inactivation by a singlet oxygen bubbler: Identifying factors controlling the toxicity of ${ }^{1} \mathrm{O}_{2}$. Environ. Sci. Technol. 2012, 46, 12098-12104.

2. DeHaven, B. A.; Tokarski, J. T.; Korous, A. A.; Mentink-Vigier, F.; Makris, T. M.; Brugh, A. M.; Forbes, M. D. E.; van Tol, J.; Bowers, C. R.; Shimizu, L. S. Persistent radicals of self-assembled benzophenone bis-urea macrocycles: Characterization and application as a polarizing agent for solid-state DNP MAS Spectroscopy. Chem. Eur. J. 2017, 23, 8315 -8319.

3. Geer, M. F.; Walla, M. D.; Solntsev, K. M.; Strassert, C. Shimizu, L. S. Self-assembled benzophenone bis-urea macrocycles facilitate selective oxidations by singlet oxygen. J. Org. Chem. 2013, 78, 5568-5578.

4. Dewal, M. B; Xu, Y.; Yang, J.; Mohammed, F.; Smith, M. D.; Shimizu, L. S. Manipulating the cavity of a porous material changes the photoreactivity of included guests. Chem. Commun. 2008, 0, 3909-3911.

5. Finkelstein, E.; Rosen, G. M.; Rauckman, E. J. Spin trapping of superoxide and hydroxyl radical: Practical aspects. Arch. Biochem. Biophys. 1980, 200 (01), 1-16.

6. de Andrade, V. S. C. and de Mattos, M. C. S. Trihaloisocyanuric Acid/Triphenylphosphine: An Efficient System for Regioselective Conversion of Epoxides into Vicinal Halohydrins and Vicinal Dihalides under Mild Conditions. Synthesis, 2016, 48 (09), 1381-1388. 